\title{
Heat exchanger selection and design analyses for metal hydride heat pump systems
}

\author{
Andrea Mazzucco \\ Department of Mechanical Engineering \\ Technical University of Denmark, Nils Koppels Allé 403, DK-2800 Kongens-Lyngby, Denmark \\ andmaz@mek.dtu.dk \\ Tyler G. Voskuilen \\ Computational Thermal and Fluid Mechanics Department, \\ Sandia National Laboratories, Albuquerque, NM, USA \\ tvoskui@sandia.gov \\ Essene L. Waters \\ School of Aeronautics and Astronautics, \\ Purdue University, West Lafayette, IN, USA \\ waters5@purdue.edu \\ Timothée L. Pourpoint* \\ School of Aeronautics and Astronautics, \\ Purdue University, West Lafayette, IN, USA \\ timothee@purdue.edu \\ Masoud Rokni \\ Department of Mechanical Engineering \\ Technical University of Denmark, Nils Koppels Allé 403, DK-2800 Kongens-Lyngby, Denmark \\ mr@mek.dtu.dk
}

*Corresponding author

(C) 2016. This manuscript version is made available under the Elsevier user license http://www.elsevier.com/open-access/userlicense/1.0/ 


\begin{abstract}
This study presents a design analysis for the development of highly efficient heat exchangers within stationary metal hydride heat pumps. The design constraints and selected performance criteria are applied to three representative heat exchangers. The proposed thermal model can be applied to select the most efficient heat exchanger design and provides outcomes generally valid in a pre-design stage. Heat transfer effectiveness is the principal performance parameter guiding the selection analysis, the results of which appear to be mildly (up to 13\%) affected by the specific Nusselt correlation used. The thermo-physical properties of the heat transfer medium and geometrical parameters are varied in the sensitivity analysis, suggesting that the length of independent tubes is the physical parameter that influences the performance of the heat exchangers the most. The practical operative regions for each heat exchanger are identified by finding the conditions over which the heat removal from the solid bed enables a complete and continuous hydriding reaction. The most efficient solution is a design example that achieves the target effectiveness of $95 \%$.
\end{abstract}

Keywords: metal hydride heat pump; metal hydride; heat exchanger; thermal analysis; sensitivity analysis

\title{
1. Introduction
}

Metal-hydride-based systems have been widely investigated as candidate technologies for hydrogen storage and thermal systems. The first category includes applications in both mobile and stationary systems [1-4] while the second is often applied for hydrogen compression [5], heat recovery and air conditioning [6, 7]. Several challenges must be overcome before such solutions provide a commercially valid alternative to existing technologies. Crucial technology gaps cut across disciplines such as material science and mechanical engineering, addressing challenges such as the characterization and the selection of the metal alloys and the design of the heat management system to be integrated in the metal hydride $(\mathrm{MH})$ bed.

In the literature, heat exchanger design has been mostly focused on applications for hydrogen storage rather than thermal systems [8-12]. The heat management systems in these two applications must fulfill different functions and therefore typically results in different designs for each. In both cases, the hydriding process dictates the design of the heat exchanger. However, the objective of the heat exchanger for a metal hydride heat pump (MHHP) is to heat the heat transfer fluid (HTF) for as long as possible; while in a hydrogen storage application its primary objective is to cool the hydride bed as rapidly as possible upon loading. Although these are complementary aspects of the same heat transfer problem, they define different performance parameters to be optimized in the heat exchanger system and thus drive the design process to different final configurations.

Various computational models and experimental studies for MHHPs have been proposed to describe the thermal cycle with attention to alloy selection [13], performance [14-16] and heat and mass 
transfers that take place in the solid bed [17-20]. However, the selection criteria and design approaches for the heat management system are typically not well-documented in the literature or rarely investigated. The selection of a particular heat exchanger, especially for experimental studies, is driven mainly by the availability of the single components rather than the result of an optimization analysis [15, 21-23]. Simple and complex computational models have been applied to describe the performance of complete thermal cycles in terms of the coefficient of performance (COP) but often lack general insights into the selection criteria for the heat exchanger [14, 20, 24, 25]. Furthermore, most studies refer to a specific metal hydride pair, making the comparison between MHHPs configurations material dependent.

In this study, we define a set of selection criteria for heat exchanger candidates and outline a general approach that can be used in the initial design stage of a metal hydride thermal system heat exchanger. The heat exchanger effectiveness is computed for each solution and a thermal analysis is performed to study the influence of different Nusselt number correlations on the performance of the various configurations. The results of the thermal model are used to select the most appropriate system among a short list of candidates, independent of the specific metal hydride composition. In addition, a sensitivity study is carried out to investigate the effect of fluid thermo-physical properties and design parameters on the performance of the proposed final configurations. Finally, we present a heat demand analysis to determine the operating points at which the system fulfills performance and design criteria while satisfying the cooling demand of the metal hydride for relevant reaction times.

\section{Motivation}

At Purdue University's Hydrogen Systems Laboratory (HSL), investigations on metal hydride systems have focused on material characterization [26-28], hydrogen storage [29-31] and, more recently, thermal applications [32]. One on-going project aims to develop a single-stage heat pump system to recover the waste heat from a high temperature fuel cell and a natural gas reformer in order to heat water for large energy-demanding utilities while increasing the overall efficiency of the system.

Interest in MHHPs has increased due to the potential advantages that such systems can provide when compared to standard compression systems. MHHPs offer the potential to increase the efficiency and operational reliability by tailoring the system to the specific required temperatures; an effect that requires the proper selection of metal hydrides. These systems also have the potential to reduce the number of moving parts required, potentially simplifying the system fabrication, setup, and maintenance. Downsides of current MHHPs include the low thermal power per unit of mass resulting in low COPs, the cyclic nature of their operation, and the high cost of some of the metal hydrides.

This work investigates the heat exchanger integrated in the hydride beds and can be considered as the second stage of a larger study; the first step of which has focused on the material selection of the hydride pairs. This first step was accomplished by Voskuilen et al. and the hydride selection results are discussed in Ref. [32]. The heat exchanger selection analysis in this work is intended to be generally applied to any promising two-hydride pair. The thermal model aims to identify the optimal heat 
exchanger for a $\mathrm{MH}$ heat pump system within the conditions and criteria introduced in the following section.

\section{Methods}

In this work, we developed a thermal model of a heat exchanger system and used it to analyze and compare three heat exchanger designs in terms of performance and capability to fulfill the energy demand of the hydride. These three designs, detailed in section 3.2, are among the most common industrially employed configurations. A general approach must be established for application to these systems regardless of the properties of the particular hydrides chosen. The heat transfer effectiveness is investigated according to the following assumptions:

- The heat transfer process is carried out under steady state conditions.

- The hydrogen absorbing process is modeled as ideal.

- The thermo-physical properties of the heat transfer fluid are kept constant during the simulation.

The design assumes time-independent conditions and the heat exchanger system is modeled to operate at steady state. This design approach is not far from reality as the present study is focused on thermally limited hydride reactions for long-cycle metal hydride heat pumps, and thus, the majority of the operation is, in practice, in a quasi-steady condition. For such an application, it is desirable to maintain the HTF at an elevated temperature during each stage of the cycle and realize sustained HTF heating during hydriding rather than rapid hydride cooling. Therefore, the rapid reaction kinetics that occurs between cycle changes and the design aspects that originate from it are out of the scope of the present study. In our system, the pressure is held constant during hydrogen absorption and the cooling rates are sufficiently high to sustain the thermally-limited reaction, but not large enough to rapidly cool the $\mathrm{MH}$. Therefore, the $\mathrm{MH}$ temperature rises at the beginning of hydriding when the solid bed experiences fast kinetics and then remains approximately constant (around the equilibrium temperature) for a long time, as the absorption reaction proceeds slowly. Only the nearly isothermal portion of the hydriding characteristic is here considered for the heat exchanger design.

With respect to an entire heat pump cycle, the heat management system must be designed to fulfill the energy demand at any stage, including the cooling and heating of the solid bed during hydriding and dehydriding, respectively. For most metal hydrides, the hydrogen absorption and desorption reaction rates are usually of comparable magnitude in terms of energy demand. It is therefore assumed that the heat exchanger solution that can fulfill the cooling demand during hydriding can easily satisfy the energy demand of dehydriding. For this reason, the present analysis is focused on the hydrogen absorption process.

For thermal design, assuming an idealized hydriding reaction, the absorption process can be attributed to a pure-substance-condensation problem in which the heat source evolves isothermally. This means that, for any metal hydride, it is possible to identify a constant temperature at which to consider the absorption reaction. This assumption better approximates the behavior of rapidly reacting 
hydrides, for which the majority of the reaction occurs at the thermodynamic equilibrium temperature, whereas for slowly reacting hydrides the disparity between the assumed constant absorption temperature and its actual value at any moment of the hydriding reaction would be more pronounced. As this study focuses on long-cycle MHHPs, fast reacting materials are to be preferred and therefore, this assumption well describes the practical operation of the system [6].

The general design approach employed in the present work is independent of the specific hydride used. It follows that the HTF temperature at the inlet and outlet cannot be precisely determined and therefore, in the following calculations, the thermo-physical properties are estimated at ambient temperature. This assumption is realistic for the end application of heating water, as the minimum temperature at which the liquid is fed to the heat exchanger is generally close to the ambient temperature $\left(20^{\circ} \mathrm{C}\right.$ in the current analysis). To avoid steam generation inside the tubes the maximum outlet temperature is limited by the boiling point of water. For this reason, it can be assumed that the outlet temperature will not exceed $90^{\circ} \mathrm{C}$ at atmospheric pressure. As a result, the mean thermo-physical properties used herein are evaluated at an average temperature of $55^{\circ} \mathrm{C}$.

The effect of thermo-physical properties on the results is addressed in the sensitivity analysis section; they are varied over a wide range of values encompassing the cases of average temperatures other than $20^{\circ} \mathrm{C}$ and the case of alternative heat transfer mediums.

\subsection{Effectiveness and index of performance}

Hydrogen storage systems for which the major goal is to rapidly cool the hydride during absorption consist of a temperature rise of the HTF across the heat exchanger that can nearly be zero. In a MHHP system, however, we must provide a significant temperature increase in the cooling fluid in order to obtain useful heating in other components in the system. For this analysis, we consider only the most energy-demanding process of the heat pump cycle (i.e. the absorption reaction) rather than the complete thermal cycle. To quantify the effectiveness of the system during the absorption stage, we define an index of performance based on the temperature change in the coolant.

With respect to the entire tube length, using the assumptions reported in the previous subsection, one can write [33]:

$$
\ln \frac{\Delta T_{\text {out }}}{\Delta T_{\text {in }}}=\frac{-\bar{U} A_{\text {hex }}}{\dot{m}_{f} C_{p, f}}
$$

where $\Delta T_{\text {out }}$ and $\Delta T_{\text {in }}$ represent the differences between the constant metal hydride temperature during hydrogen absorption and the mean outlet and inlet fluid temperatures, respectively. $\bar{U}$ is the average overall heat transfer coefficient, $A_{\text {hex }}$ is the heat transfer area, $\dot{m}_{f}$ is the HTF mass flow rate, and $c_{p, f}$ is the specific heat capacity.

In order to define an index of performance, the previous equation is rearranged as: 


$$
F=\frac{T_{M H}-T_{f-m, \text { out }}}{T_{M H}-T_{f-m, \text { in }}}=\exp \left(\frac{-\bar{U} A_{\text {hex }}}{\dot{m}_{f} c_{p, f}}\right)
$$

where $F$ is the index of performance representing the fluid temperature increase from the inlet conditions, $T_{f-m, i n}$, to the outlet, $T_{f-m, \text { out }}$, and $T_{M H}$ is the metal hydride temperature that evolves isothermally during hydrogen absorption. The parameter $F$ defines the realized fraction of the total coolant temperature increase as a dimensionless ratio of temperature differences between the hot source (i.e. the metal hydride that undergoes an absorption reaction) and the hot outlet and cold inlet fluid. This metric indicates how well the heat transfer process is performed. With constant $\mathrm{MH}$ and fluid inlet temperatures, lower $F$ values correspond to higher outlet temperatures and consequently, better performance. According to the assumption that the $\mathrm{MH}$ temperature evolves isothermally, the following relation, can be applied for condensation problems:

$$
\varepsilon=1-F
$$

where the heat exchanger effectiveness, $\varepsilon$, is related to the index of performance. The index of performance is only dependent upon design variables, heat and mass transfer parameters and fluid properties. Further details on the effectiveness, $F$ formulations, and the models used for the different heat exchangers are given in the thermal model section.

\subsection{Heat exchanger configurations and design criteria}

Since some of the promising hydride pairs identified in Ref. [32] for a MHHP application exhibit relatively high equilibrium pressures, the vessel containing the absorbing alloy must be cylindrical in shape to allow for a uniform distribution of the mechanical stresses that result from pressurization. Under such a constraint, the heat-exchanger vessel designs chosen for the analysis are of a shell-andtube configuration, a common heat exchanger configuration.

Three configurations of shell-and-tube heat exchangers are considered in this work, described as HEX1, HEX2, and HEX3. In configuration HEX1, the coolant flows inside tubes which are surrounded by metal hydride. In HEX2, the metal hydride is packed inside the tubes and the coolant flows parallel to the tube. Finally, in HEX3, the metal hydride is packed inside the tube but the coolant circulates in a combined cross-parallel flow over the tube bank. These arrangements are shown in Fig. 1. For the model presented, it is assumed that each tube represents a stand-alone heat transfer module and that the number of tubes only affects the overall heat transferred and not the flow conditions or heat transfer characteristics. 


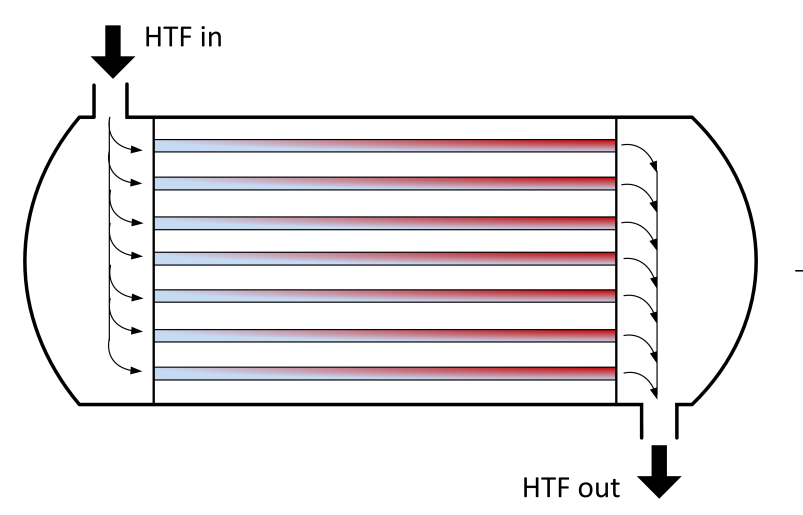

(a)

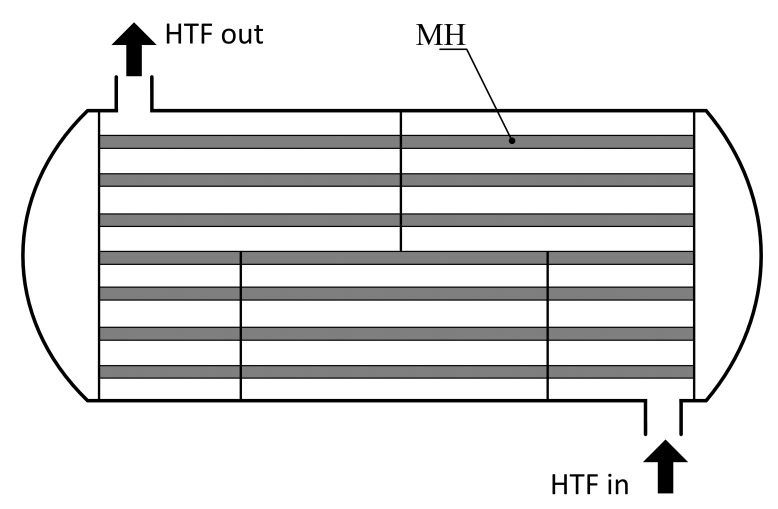

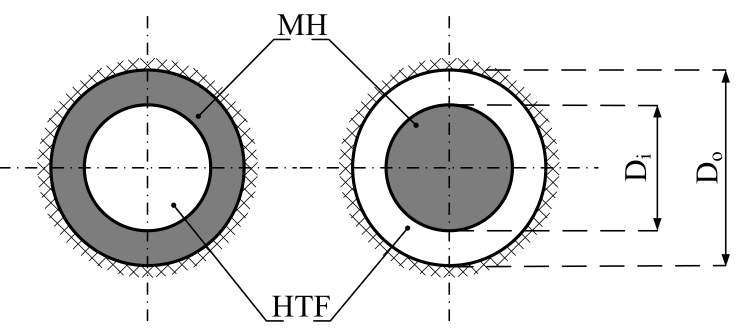

(b)

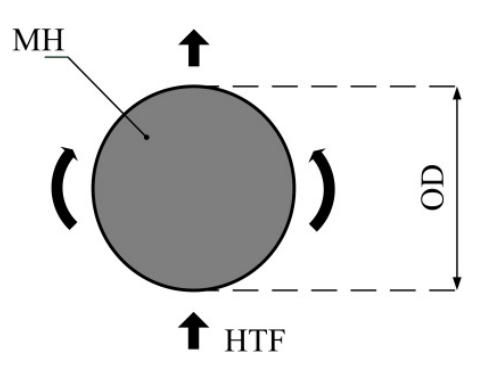

(c)

Figure 1. Longitudinal section for HEX1 and HEX2 (a); transversal sections for HEX1 and HEX2 with external adiabatic boundary (b); longitudinal and transversal sections for HEX3 (c). OD is the outer diameter.

The other configuration presents a mirror arrangement of the solid and fluid domains and is shown in Fig. 1 (c) with its longitudinal and transversal sections. The MH bed is composed of single modules and the heat is transferred through the tube thickness to the HTF that flows over the tube bank in a combined cross-parallel flow.

System selection is made by evaluating the effectiveness and resulting size of the proposed designs that satisfy the performance and operative requirements listed in Table 1 . The fluid velocity interval identified in the table (i.e. $1 \leq v \leq 2.5 \mathrm{~m} / \mathrm{s}$ ) is used as the optimum velocity range, since water velocities below $1 \mathrm{~m} / \mathrm{s}$ can lead to deposit formation, while velocities above $2.5 \mathrm{~m} / \mathrm{s}$ increase corrosion for most common aluminum/copper alloys and contribute to tube vibrations [34]. However, it should be noted that lower minimum velocities are practicable when demineralized water is used and velocities around $0.8 \mathrm{~m} / \mathrm{s}$ are often used in practice. 
Table 1. List of performance and operative requirements to be satisfied.

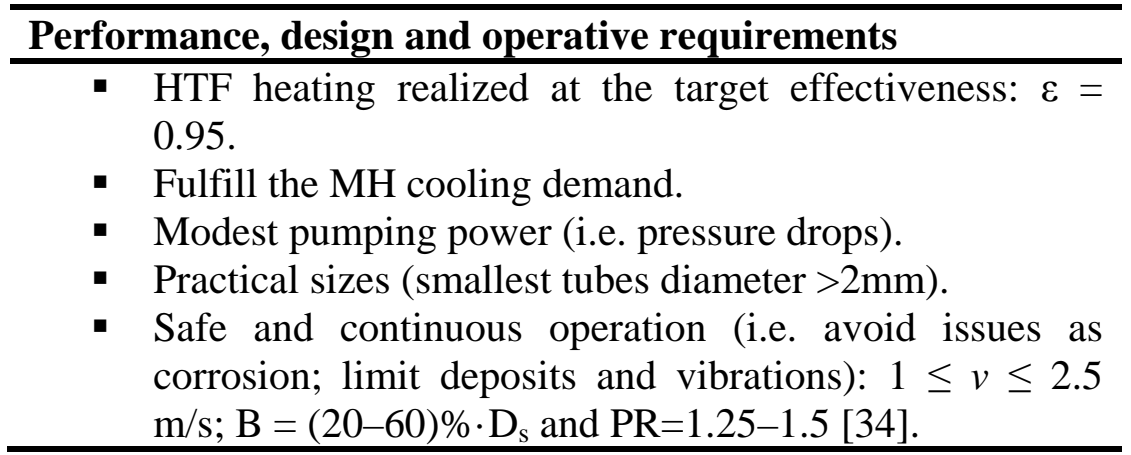

In Table $1, v$ is the HTF velocity, $B$ is the relative baffle space expressed as percentage of the inner shell diameter $D_{s}$, and $P R$ is the pitch to tube-diameter ratio.

\subsection{Thermal model}

The following procedure and set of equations were implemented in Matlab ${ }^{\circledR}$ to compute the performance and pressure losses for each heat exchanger. The inputs of the model consist of the HTF velocity and the flow path and heat transfer geometries.

The hydraulic diameter, $D_{h}$, for HEX1, HEX2 and HEX3 is defined by Eqs. (4.a)-(4.c), respectively:

$$
\begin{gathered}
D_{h}=D_{i} \\
D_{h}=D_{o}-D_{i} \\
D_{h}=D_{o}
\end{gathered}
$$

A value for the total active length of the tube is assumed for each configuration. For HEX2 and HEX3 it corresponds to the MH tube length, while for HEX1 it is defined as,

$$
L_{\text {tot }}=N_{p} \cdot L_{\text {tube }}
$$

where $N_{p}$ is the number of passes and $L_{\text {tube }}$ is the single-tube length actively involved in the heat transfer process. For HEX2 and HEX3, other input parameters are required to completely define the geometry. For HEX2, only the aspect ratio $a$ is needed and is defined as

$$
a=\frac{D_{i}}{D_{o}}
$$

This equation is coupled with Eq. (4.b) and used to determine $D_{o}$ and $D_{i}$ for any given values of $a$ and $D_{h}$. 
For HEX3, the other main geometrical inputs include the inner diameter of the shell, $D_{s}$, the segmental baffle cut (25-35\%), the tube-pitch layout, and the parameters listed in Table 2:

Table 2. List of the main additional geometric parameters used in the analysis for HEX3.

\begin{tabular}{l|lll}
\hline Parameter & Symbol & Value & Ref. \\
\hline Relative baffle space $\left(\%\right.$ of $\left.\mathrm{D}_{\mathrm{s}}\right)$ & $B$ & $20 \%$ & {$[34]$} \\
Pitch to tube-diameter ratio & $P R$ & 1.25 & {$[34]$} \\
Temperature factor & $F_{t}$ & 0.875 & {$[33]$} \\
Tube count calculation constant for one tube pass & $C T P$ & 0.93 & {$[35]$} \\
Tube layout constant & $C_{t}$ & 0.87 & {$[35]$} \\
\hline
\end{tabular}

The chosen values of $B, P R$ and $F_{t}$ and their influence on fluid flow, mechanical strength of components and heat transfer are discussed in the sensitivity analysis section. The tube count constant, CTP, accounts for the imperfect coverage of the shell diameter by the tubes due to necessary clearances between the shell and the outer tube circle and its assumed value refers to one tube pass, as it is the closest condition to the case here considered. The value for $C_{t}$ applies for a tube layout inclined by 30 or 60 degrees and was chosen due to the increased tube density that it provides for any given $D_{s}$, and thus was expected to realize a greater temperature increase in the HTF. Performance results have confirmed such a prediction when the $C_{t}$ value valid for a layout angle of 45 and 90 degrees was employed in the simulations. Similar conclusions can be drawn when a triangular tube pitch is used in place of a squared pitch.

The cross flow areas are computed by means of the following equations for HEX1, HEX2 and HEX3 respectively:

$$
A_{\text {cross }}=\left[\begin{array}{l}
\pi \frac{D_{h}^{2}}{4} \\
\frac{\pi}{4}\left(D_{o}^{2}-D_{i}^{2}\right) \\
\frac{B \cdot D_{s}^{2} \cdot C_{l}}{P_{t}}
\end{array}\right.
$$

where $P_{t}$ is the tube pitch calculated via $P R$ and $D_{o}$ and $C_{l}$ is the tube clearance defined according to Ref. [33].

Next, all the parameters required to estimate $P_{r}$ and $R e$ must be calculated. For HEX3, these parameters include the maximum number of tubes that fit the prescribed inner shell volume and the equivalent diameter, according to the design procedure reported in Ref. [35].

The pressure drops are calculated by means of the friction factor for the laminar and turbulent regimes given in Ref. [36] for HEX1 and in Refs. [37, 38] for HEX2. For HEX1, the Churchill equation is used in the turbulent regime for ease of computation [39]. Due to the lack of a dedicated 
correlation for the friction factor in the transition region, an interpolation between the values calculated in laminar and turbulent regimes is proposed in the appendix. For HEX3, the pressure drops are estimated by means of the Kern method [35], the validity of which is addressed in the results section. In the friction factor correlations, a value of $1.118 \times 10^{-6}$ is assumed for the roughness of the smooth aluminum tubes when applicable [40].

The $\mathrm{Nu}$ number is computed according to the nominal correlations described in the appendix. The effectiveness, $\varepsilon$, is calculated for each configuration by means of Eq. 3 where the index of performance defined in Eq. 2 can be re-written by separating the variables as

$$
\begin{gathered}
F=\exp (-1) \cdot \exp \left(\frac{A_{\text {hex }}}{A_{\text {cross }}}\right) \cdot \exp \left(\frac{1}{\rho_{f} \cdot c_{p, f}}\right) \cdot \exp \left(\frac{\bar{h}_{f}}{v}\right) \\
G=\frac{A_{\text {hex }}}{A_{\text {cross }}} ; P=\frac{1}{\rho_{f} \cdot c_{p, f}} ; V=\frac{\bar{h}_{f}}{v}
\end{gathered}
$$

It is then possible to identify the three main exponential terms dependent upon geometries of heat transfer and flow, $G$, HTF thermo-physical properties, $P$, and model variables, $V$. For model variables, the assumption $\bar{h}_{f}=\bar{U}$ is applied for HEX1 and HEX2, while for HEX3 such relation reads: $F_{t} \cdot \bar{h}_{f}=\bar{U}$.

Finally, $G$ can be made explicit by using the expressions for heat transfer area and mass flow rate for each heat exchanger to see the influence of the input terms on the performance. As a result we obtain Eqs. (9.a) to (9.c) for HEX1, HEX2 and HEX3, respectively:

$$
G=\left[\begin{array}{l}
\frac{4 \cdot L_{t o t}}{D_{h}} \\
\frac{4 \cdot L_{t o t}}{D_{h} \cdot\left(\frac{1}{a}+1\right)} \\
\frac{\pi \cdot L_{\text {tube }} \cdot C_{1}}{B \cdot P R \cdot(P R-1)}
\end{array}\right.
$$

where Eq. (9.b) is obtained by using Eqs. (4.b), (6) and (7.b).

In Eq. (9.c), $C_{1}$ is a constant defined as:

$$
C_{1}=0.785 \cdot \frac{C T P}{C_{t}}
$$


For HEX3, the geometric term is independent of the number of tubes, $D_{s}$, and the characteristic length under the prescribed assumptions. As a result, $G$ is a constant for any simulations of HEX3 where the tube length does not vary. For HEX1 and HEX2, $G$ depends on the hydraulic diameter and the aspect ratio. The dependency of $\varepsilon$ upon the characteristic length is found in the $\bar{h}_{f}$ term according to the Bell-Delaware method described in the appendix. A more explicit formulation for $F$ can be used when it is possible to express $\bar{h}_{f}$ as a function of $N u$, fluid thermal conductivity, and characteristic length by rearranging these parameters into their respective exponential terms.

\subsection{Limitations of the analysis}

The metal hydride heat pump system is a cyclic system in which all processes are time dependent and thus, the present steady-state analysis should be considered a pre-design study to select the most efficient configuration in terms of the heat transfer effectiveness. A more complete design analysis would require the estimation of the actual COP for an entire time-dependent cycle. In addition, variable properties should be considered for the heat transfer medium once its inlet and outlet temperatures and the hydride pair are defined. The study relies on a single-phase HTF with the approximate properties of water at $55{ }^{\circ} \mathrm{C}$. It follows that, if the hydride exceeds the boiling point of water, a suitable alternative HTF must be selected.

Finally, it was assumed that the process limiting the heat transfer is the convective resistance of the HTF, shown by $\bar{U}=\bar{h}_{f}$ in Equations (1)-(3). In an actual design, sufficiently small metal hydride thicknesses and significant thermal enhancement are required to achieve such a condition. Simulations carried out in the present study have shown that a solid thermal resistance of $2.5 \times 10^{-4} \mathrm{~m}^{2} \cdot \mathrm{K} \cdot \mathrm{W}^{-1}$ would be generally necessary in the diameter-velocity space considered here. This value could be obtained by employing a bed thickness of either $0.25 \mathrm{~mm}$, referring to a thermal conductivity of $1 \mathrm{~W} \cdot \mathrm{m}^{-1} \cdot \mathrm{K}^{-1}$, or 2.5 $\mathrm{mm}$ in presence of thermal enhancement up to $10 \mathrm{~W} \cdot \mathrm{m}^{-1} \cdot \mathrm{K}^{-1}$ [41]. However, to optimize a configuration for a particular hydride pair, the model can be readily modified to include the actual thermal conductivity, leaving the thickness as a variable of optimization.

\section{Results}

In this section, the performance and size of each configuration is addressed with attention to design and operation conditions. The effectiveness and distributed pressure drops for smooth aluminum tubes are evaluated over a wide range of operating conditions and the most efficient regions are identified. This analysis provides information on the major dimensions of the heat exchanger and the range of fluid velocities convenient for system operation. Various correlations for the estimation of the Nusselt number are used to investigate their influence on the design process. The sensitivity analysis provides additional information on the effect of design parameters and HTF properties on the performance of the heat exchanger. Finally, the heat demand analysis details the actual operational regions that the system can be operated over while satisfying the cooling demand of the hydride. 


\subsection{Analysis of performance and pressure drops}

The thermal model presented in the previous section is used to compute the heat exchanger effectiveness and pressure drops for each layout. The two main variables considered for each design are the tube diameter and coolant flow rate. For HEX1 and HEX2 we consider diameters up to $10 \mathrm{~mm}$; for larger tube sizes the performance assumes very low values that are not of interest for this design. For the same reason, the maximum tube size considered for HEX3 is $40 \mathrm{~mm}$. For all the heat exchangers, the flow velocity is limited to $5 \mathrm{~m} / \mathrm{s}$. In Figs. 2-4 we present the effectiveness and pressure drop over this range of values. For HEX1and HEX2 the diameter considered is the tube hydraulic diameter, $D_{h}$, while for HEX3, the outer tube diameter $O D$ is considered as the characteristic length. The dashed lines in the figures show the boundaries between laminar, transitional, and turbulent flow.

Fig. 2 (a) shows three different regions for the different flow regimes the system is operating in. The highest efficiencies, above 0.9, are where the small hydraulic diameter ensures high heat transfer coefficients regardless of the flow velocity; for this layout the hydraulic diameter is the tube inner diameter. As expected, the combination of low velocities and small diameters provides the greatest $\varepsilon^{-}$ values, requiring the system to be designed for the size typical of mini-tube heat exchangers. With the limitation that the coolant velocity remain between $1 \mathrm{~m} / \mathrm{s}$ and $2.5 \mathrm{~m} / \mathrm{s}$ to avoid deposits and prevent corrosion in the aluminum tubes, it is not possible to achieve an effectiveness of 0.9 for diameters greater than $2 \mathrm{~mm}$. For velocities in this range, the transition regime, shown between the black dashed lines, provides the highest practical efficiencies (excluding the region where $D_{h} \rightarrow 0$ ). However, it is generally not recommended to operate the system in the transition regime because the sudden fluctuations from laminar to turbulent flow cause the thermal performance to be unpredictable and discontinuous. A maximum effectiveness of 0.8 can be obtained in the turbulent regime at velocities of around $4.5-5 \mathrm{~m} / \mathrm{s}$, while lower $\varepsilon$-values, $0.25-0.6$, can be achieved in the optimum velocity range and for diameters greater than $4 \mathrm{~mm}$. The pressure drop shown in Fig. 2 (b) indicates regions where pumping power may become too large to be practical. At $1.75 \mathrm{~m} / \mathrm{s}$, the maximum loss is approximately 2 bar for practical diameters and the minimum loss is approximately 0.04 bar for $D_{h}=10 \mathrm{~mm}$. It is important to note that these values refer to the overall system and are independent of the total number of tubes as these are connected in a parallel arrangement (see Fig. 1 (a)). The diagonal red lines represent a region where the calculated pressure drop exceeds $15 \mathrm{bar}$, is a value selected for ease of reading. For velocities below the optimum range considered in this study, pressure drops measurements are available for HEX1 for an inner tube diameter of $4.57 \mathrm{~mm}$ in Ref. [42]. 

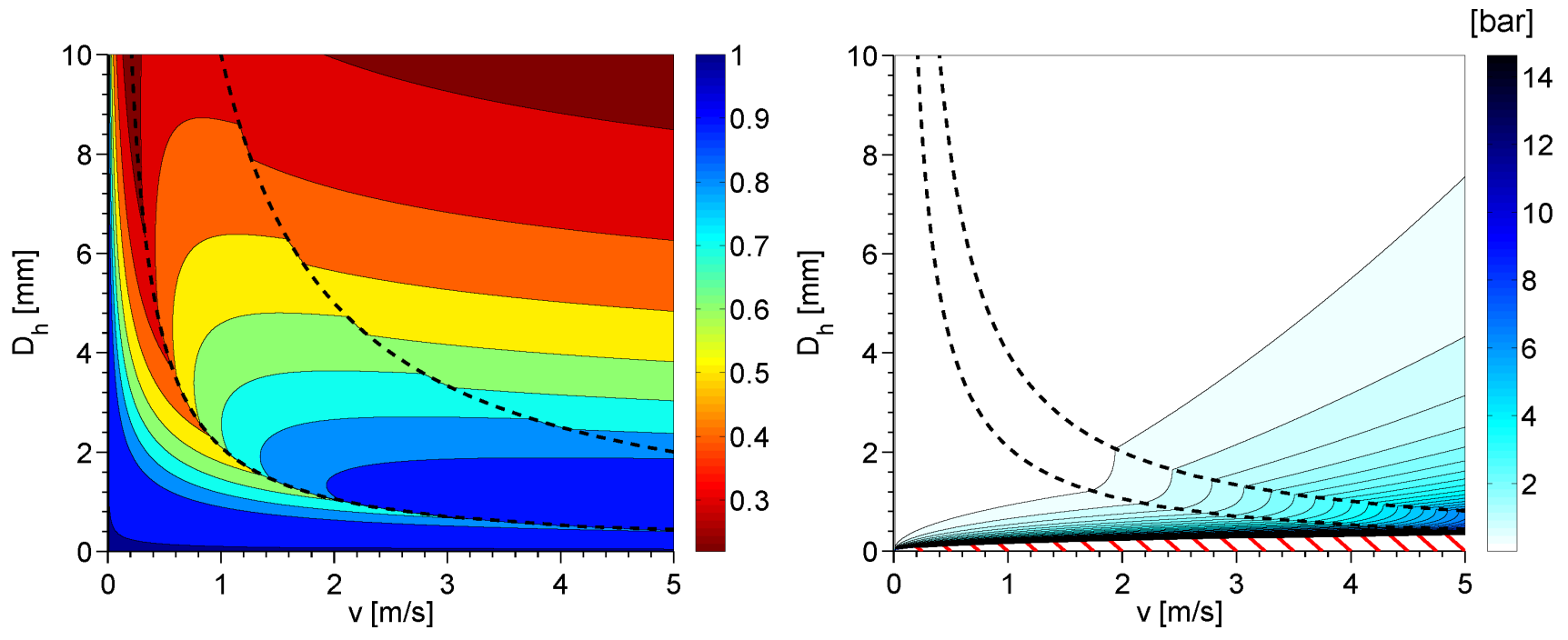

Figure 2. Effectiveness map (a); distributed pressure drops (b) for $\mathrm{L}_{\mathrm{tot}}=1 \mathrm{~m}-\mathrm{HEX} 1$.

Fig. 3 (a) shows the results of the performance analysis for HEX2. This layout provides generally lower performance than HEX1 for all regimes, and efficiency values above 0.8 are only possible at significantly small hydraulic diameters $(<1 \mathrm{~mm})$ and/or velocities $(<0.2 \mathrm{~m} / \mathrm{s})$. For any given velocity, the effectiveness of heat transfer decreases from laminar to turbulent regions; in the latter it is not possible to achieve $\varepsilon$-values above 0.45 . In the optimum velocity range, the transition to turbulent flow conditions occurs for a hydraulic diameter between $4 \mathrm{~mm}$ and $10 \mathrm{~mm}$. With respect to the pressure drop analysis, conclusions similar to those discussed for HEX1 can be drawn for HEX2 and the main outcomes identified from Fig. 2 (b) are also valid for Fig. 3 (b).

For HEX2, operation in the laminar region is generally not advisable; the $\varepsilon$-regions are much narrower than for the other regimes, making it difficult to operate the system continuously at a selected effectiveness value. 
[bar]
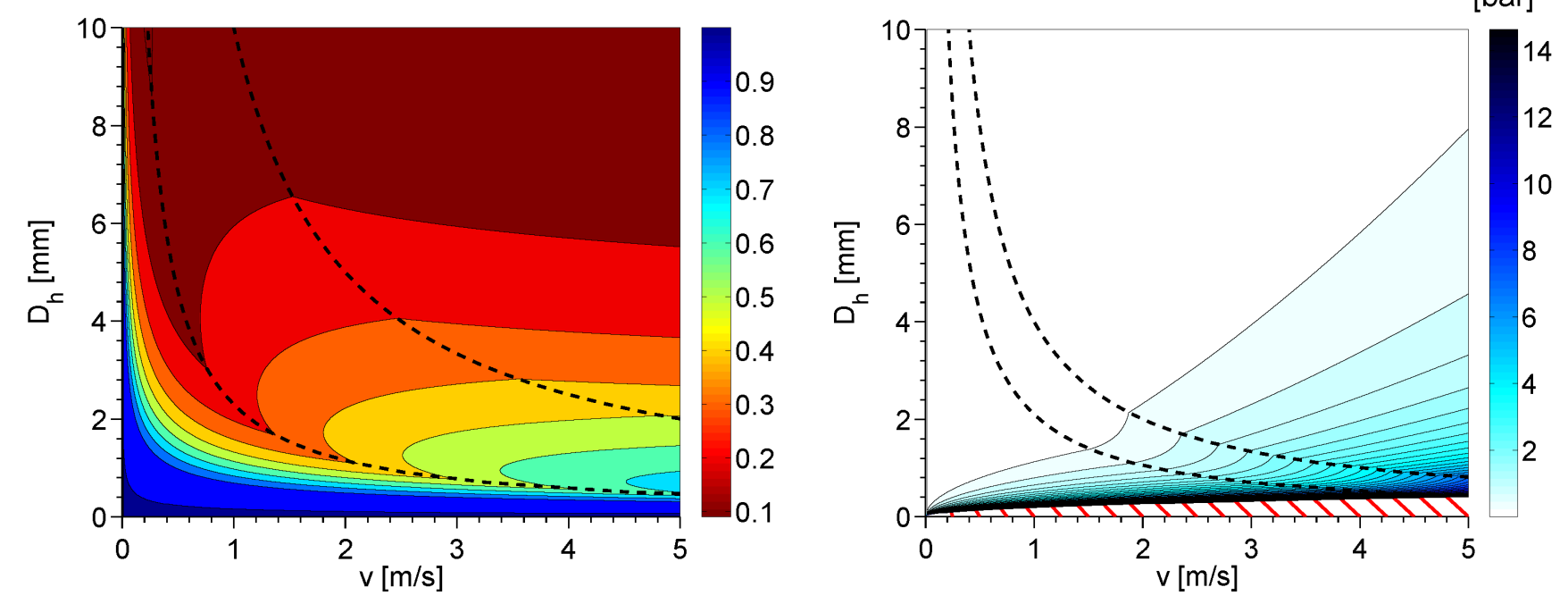

Figure 3. Effectiveness map (a); distributed pressure drops (b) for $\mathrm{L}_{\mathrm{tot}}=1 \mathrm{~m}$ and a=0.5 - HEX2.

From Fig. 4 (a), it is apparent that HEX3 provides the greatest performance of the three candidates. Unlike the other two designs, the effectiveness varies significantly for tubes diameters larger than 10 $\mathrm{mm}$ and for this reason, the analysis extended beyond such a value and up to tube sizes that correspond to poor performance. No noticeable change in shapes of the $\varepsilon$-regions is observed since the transition from laminar to turbulent flow conditions is smooth due to the use of a modified version of the BellDelaware method [35]. Effectiveness values close to or above 0.9 can be obtained for a wide range of tube diameters and fluid velocities. Considering the requirements listed in Table 1 for the optimum velocity range and practical outer tube diameters $(>2 \mathrm{~mm})$, the system can function in the turbulent regime where the accuracy of the heat transfer correlations is higher and the fluid flow conditions are stable. 

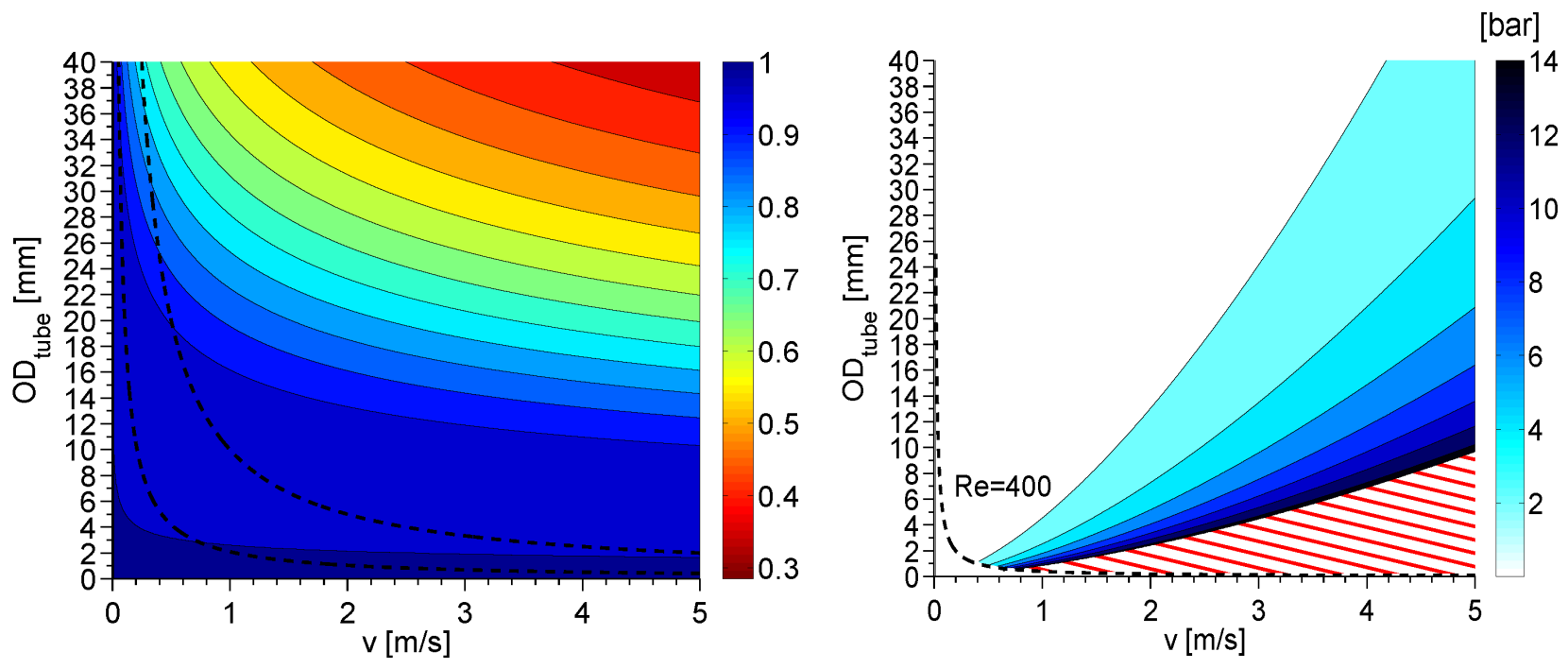

Figure 4. Effectiveness map (a); distributed pressure drops (b) for $\mathrm{L}_{\text {tube }}=1 \mathrm{~m}$ and $\mathrm{D}_{\mathrm{s}}=0.3 \mathrm{~m}-\mathrm{HEX} 3$

For a given velocity the pressure drops in HEX3 are greater than in HEX1 and HEX2 for any values of the characteristic length. As the equation employed (i.e. Kern method) is only valid for $400<\operatorname{Re}<10^{6}$ [35], the results under the dashed line in Fig. 4 (b) are not shown. However, such a limitation does not affect the main conclusions that can be drawn for HEX3, as it refers to a region with non-practical tube sizes and/or very small velocities. Reasonable values can be obtained for outer diameters above $9 \mathrm{~mm}$ where the effectiveness assumes values around 0.9. For instance, a loss of 0.7 bar can be achieved at $v_{o, m}$ for $\mathrm{OD}=10 \mathrm{~mm}$. As mentioned before, the use of demineralized water can allow the operation at low velocities with reduced risks of debris formation, moving the operational point towards lower pressure drops. However, unlike the other heat exchangers, high performance values and reasonable pressure losses for HEX3 can be achieved in the turbulent regime within the optimum velocity range. Therefore, there is no need to operate with demineralized water and low velocities to gain a modest performance enhancement.

As the following sensitivity analysis will show, a reliable way to enhance the effectiveness for any configuration is to increase the heat transfer area by increasing the total length of the tubes from the base case reported here $\left(\mathrm{L}_{\mathrm{tot}}=1 \mathrm{~m}\right)$.

\section{2 $\mathrm{Nu}$ correlation analysis}

The results presented previously have been obtained by using the nominal $\mathrm{Nu}$ correlations. In this section, we explore the effects of other correlations. For HEX1 and HEX2, the effect on the results is accounted for by displaying the influence on both $N u$ and $\varepsilon$ values at the mean optimum velocity. For HEX3, since only two correlations are explored, it is more convenient to present their effect on the heat transfer effectiveness by displaying the relative difference of the performance for the entire domain of 
velocities and outer diameters. Nominal and other investigated correlations are reported in the appendix for each configuration.

In Fig. 5, the lines marked with a star symbol represent the nominal correlations employed in the calculations above, while the other lines indicate the alternative correlations as labeled in the legend. In both Fig. 5 (a) and (b), the solid lines refer to the $N u$ values reported on the left y-axis, while the dashed blue lines represent the calculated $\varepsilon$-values on the right y-axis. Finally, the vertical lines display the Reynolds number validity thresholds for the nominal correlations as reported in the appendix (i.e. $R e_{\text {Lam }}=2100$ or 2300 and $\mathrm{Re}_{\text {Turb }}=10^{4}$ ). The transitions at these lines are the reason for the abrupt changes of the $\varepsilon$-values and $N u$.

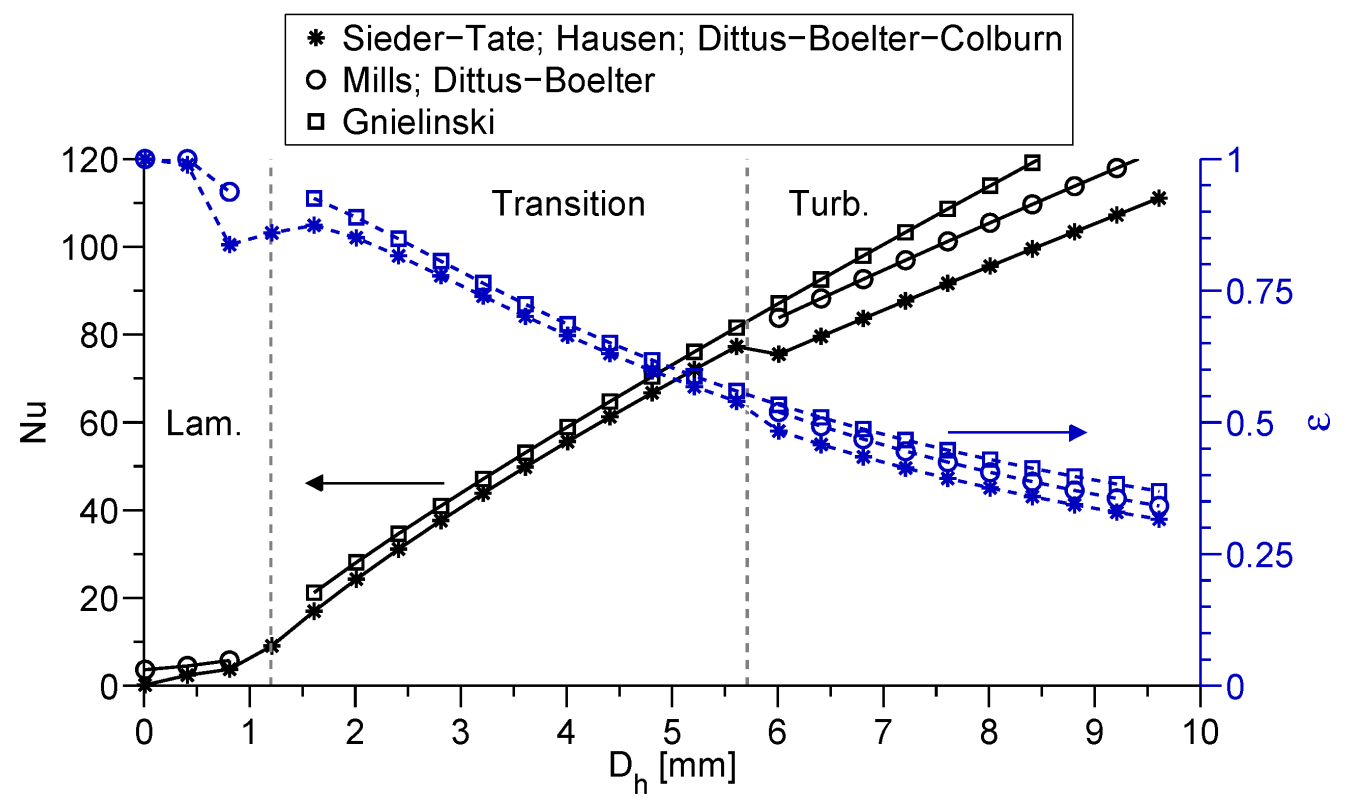

(a) 


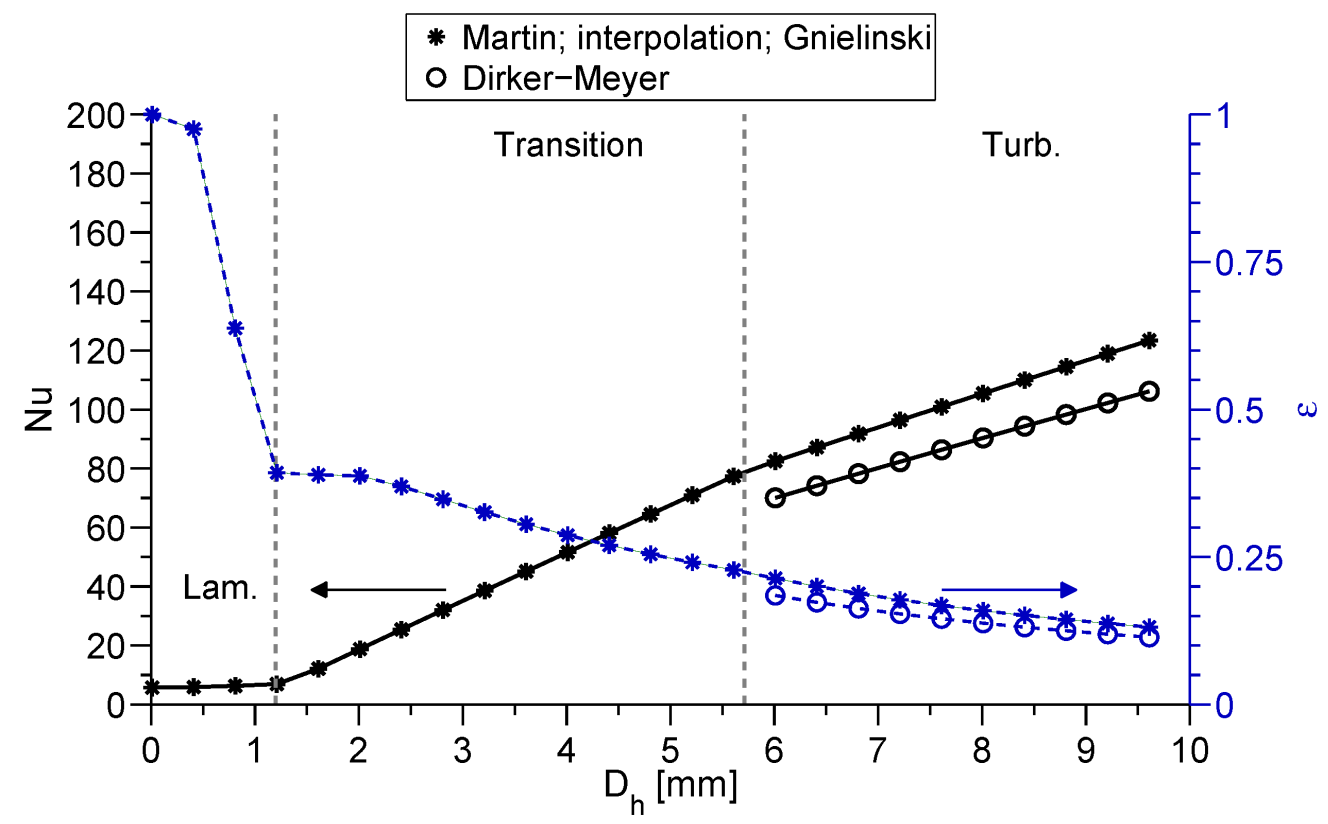

(b)

Figure 5. $N u$ and $\varepsilon$ values for different correlations with $\mathrm{v}=1.75 \mathrm{~m} / \mathrm{s}$. HEX1 (a); HEX2 (b).

Fig. 5 (a) shows that the greatest discrepancies in $N u$ occur in the turbulent regime. In this region, the maximum relative difference for $\mathrm{Nu}$ increases up to $9 \%$ when employing the simple version of the Dittus-Boelter correlation [33] and up to 16\% when the Gnielinski correlation [33] is used. However, it should be noted that their impact on the effectiveness is more modest and accounts for $7.3 \%$ and $13 \%$, respectively. Another relatively significant discrepancy in the value occurs in the laminar region when the Mills equation [43] is used. In this case, a maximum relative difference for $\mathrm{Nu}$ of $34.6 \%$ causes a variation of only $10.7 \%$ in the effectiveness value. This apparent disparity with the trend discussed for the turbulent regime can be explained by considering that the exponential nature of the $\varepsilon$-equation makes the function less sensitive to the $N u$ variation for $\varepsilon$-values closer to unity.

For HEX2, only one alternative equation has been investigated for an aspect ratio $a=D_{i} / D_{0}=0.5$, as a detailed correlation study for concentric annuli was carried out in Ref. [44] where the Dirker-Meyer equation was proposed for the turbulent region. Such a correlation underestimates the mean $\mathrm{Nu}$ by $16 \%$ when compared to the Gnielinski equation, in agreement with the results presented in Ref. [45]. Although the influence on $\varepsilon$ is not significant, accounting for only about $11 \%$, it should be mentioned that, in the study by Gnielinski, doubts on the reliability of the data processing and experimental facility have been raised for the Dirker-Meyer correlation. For this reason, the Gnielinski equation was employed as the nominal correlation for the thermal analysis in this work.

Fig. 6 shows the relative difference in the effectiveness calculation when the Bell-Delaware method (nominal correlation) is employed in place of the simpler Kern method. The former is universally 
considered to be the most accurate for the estimation of the average heat transfer coefficient on the shell side [35] with a mean error of $15 \%$ [46]. The figure shows the application of both methods in the entire domain under study; although the Kern method is only valid for the turbulent regime (i.e. above the upper dashed line that corresponds to $\mathrm{Re}_{\mathrm{Turb}}=10^{4}$ ), while the Bell-Delaware method provides performance values greater by up to $16 \%$. The opposite trend can be seen in part of the transition and laminar regions, where the Bell-Delaware method results in a relative difference of about -2\%.

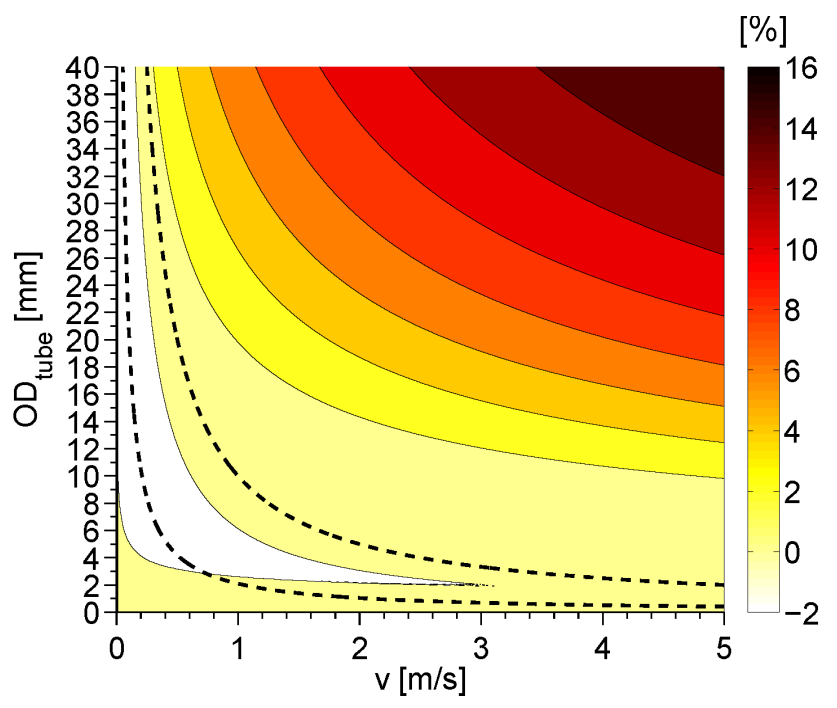

Figure 6. Relative difference in [\%] for $\varepsilon$ between the Bell-Delaware and Kern methods.

\subsection{Sensitivity analysis}

A sensitivity study was carried out to evaluate the effect of both the design and HTF thermophysical properties on the performance results using the mean optimum velocity of $1.75 \mathrm{~m} / \mathrm{s}$ and the mean characteristic length defined as half of the diameter range here investigated. The mean diameter corresponds to $5 \mathrm{~mm}$ for the less efficient configurations, namely HEX1 and HEX2, and to $20 \mathrm{~mm}$ for HEX3. From the sensitivity analysis perspective, such values are selected in order to leave room for effectiveness variation while representing practical sizes. In Fig. 7, each parameter on the left side of the box is alternatively varied, while the others are kept constant during the simulation. The effect on the effectiveness is reported on the x-axis for each parameter. The vertical red lines in each blue box represent the conditions which meet the target effectiveness of 0.95 , while the values above such a line correspond to the nominal parameters' values. For the fluid properties, these values for water at $20^{\circ} \mathrm{C}$ as discussed in the previous section.

The numbers reported by the whiskers are the upper and lower limits in the parameters' variation range, while the extremities of each blue box refer to a parameter value of $25 \%$ and $75 \%$ in the corresponding range. The variation range encompasses the properties' values of water and other common heat transfer pure-fluids between $20^{\circ} \mathrm{C}$ and $100^{\circ} \mathrm{C}$ [47, 48]. 
As one could expect, an increase in the thermal conductivity of the HTF and a decrease in its specific thermal capacity and density provides a benefit to the performance. However, it should be noted that lowering $\rho$ and $c_{p}$ causes the thermal capacity to decrease, suggesting a tradeoff between an increase in the performance and a decrease in the heat that can be removed from the $\mathrm{MH}$. It follows that even if the effectiveness is augmented, lower cooling capacities occur, making it more difficult to fulfill the cooling demand of the absorbing alloy. The kinematic viscosity seems to have a significant impact on the heat transfer effectiveness. However, the minimum and maximum values in viscosity variation range vary by an order of magnitude of 3 , which is much larger than for the other physical properties. It is thus more pertinent to consider the effect on the performance due to the parameters that are directly part of the design process.

A comparison between the two layouts reported in Figs. 7 (a)-(b) shows that the same tube length provides much lower performance for HEX2 than HEX1, as was expected by examining Figs. 2 (a) and 3 (a). In order to reach the desired value of $95 \%$ for $\varepsilon$, HEX2 needs to be more than 3 times longer when nominal parameters' values are considered. This outcome suggests that HEX1 can achieve the same performance as HEX2 with a reduced size, which in turn makes it a better candidate design for applications where volume constraints are more stringent or where the size of the system needs to be modest for experimental purposes (e.g. lab-scale systems). However, in order to have a wider view of the problem, the results from the heat demand analysis discussed in the following section should also be considered. For HEX2, the aspect ratio $a$ is varied between 0.01 and 0.99 , close to the limiting conditions of a circular tube of diameter $D=D_{h}$ with an "infinitesimal" thin wire at the center and the parallel plate case, respectively. The former condition provides greater $\varepsilon$-values per unit total length of active tube and is geometrically equivalent to the HEX1 solution. Alternatively, when the coaxial tube configuration approaches the parallel plate geometry, a significant drop in the performance can be seen, making the aspect ratio the most influential parameter within the ranges considered here.

The high performance per unit size of HEX3 makes this configuration convenient for use in a MHHP application. Indeed, Fig. 7 (c) shows that a tube length of approximately $1.7 \mathrm{~m}$ is required to reach the target effectiveness at nominal conditions. The temperature factor, $F_{t}$, takes into account the direction of the flow over the tube bank and has a marginal effect in the range considered. The minimum value for such a factor is limited to 0.75 as it is typically not convenient to manufacture a heat exchanger with lower values [33]. The effect of the relative baffle spacing, $B$, and the tube to pitch ratio, $P R$, is explored for values that exceed the recommended optimum range reported in Table 1. From a performance point of view, the lower these parameters are the greater the heat transfer effectiveness will be. Relative baffle spacings smaller than $20 \%$ of the inner shell diameter should be excluded due to the negative effect on the flow circulation and deposit and values lower than 1.25 for $P R$ are not recommended as they embrittle the tube sheet [34]. For these reasons, the nominal values for these two parameters have been set equal to the lower limits of their respective optima ranges, to provide the highest performance. As described earlier, the shell diameter, $D_{s}$, does not influence the performance and thus its variation is not considered in this sensitivity analysis. 
It should be noted that given the velocity and characteristic length conditions used in this sensitivity analysis, the operational point falls within the transition regime for HEX1 and HEX2 and within the turbulent regime for HEX3. However, the trend and main outcomes determined from Fig. 7 are still valid for any velocity and characteristic length values.

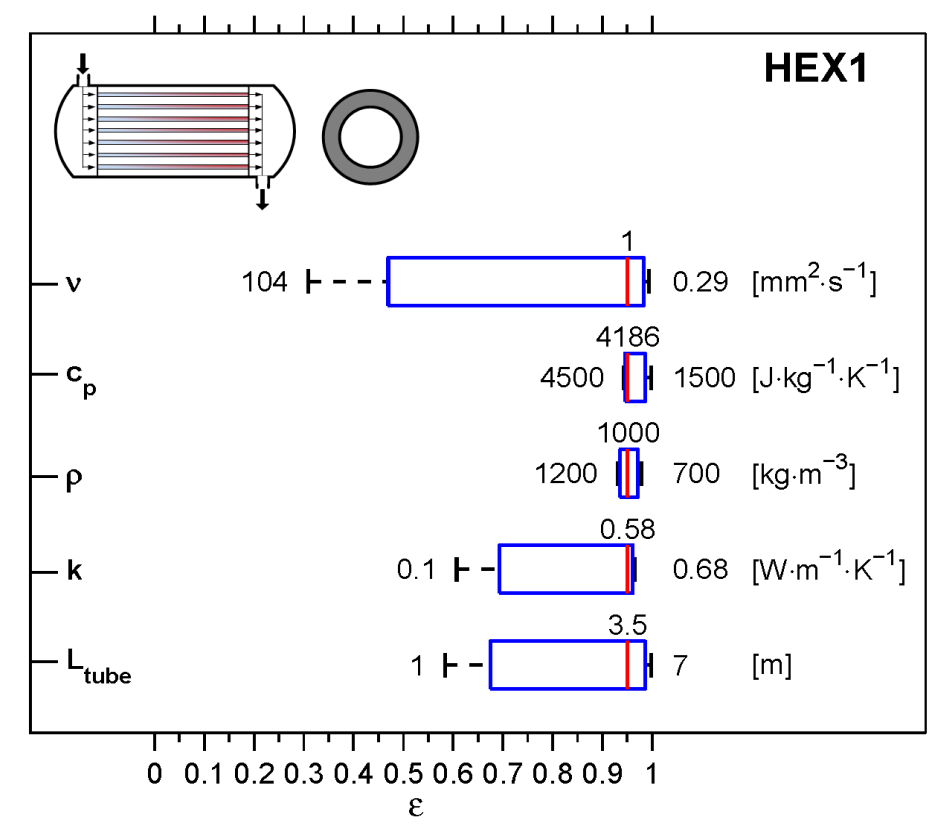

(a)

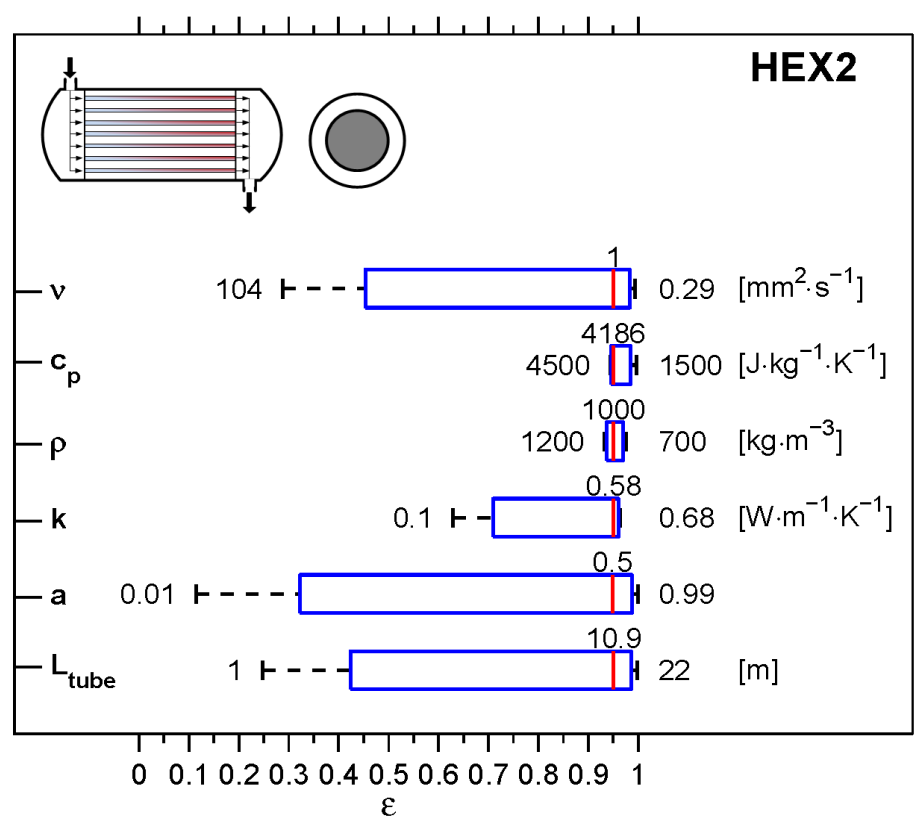

(b) 


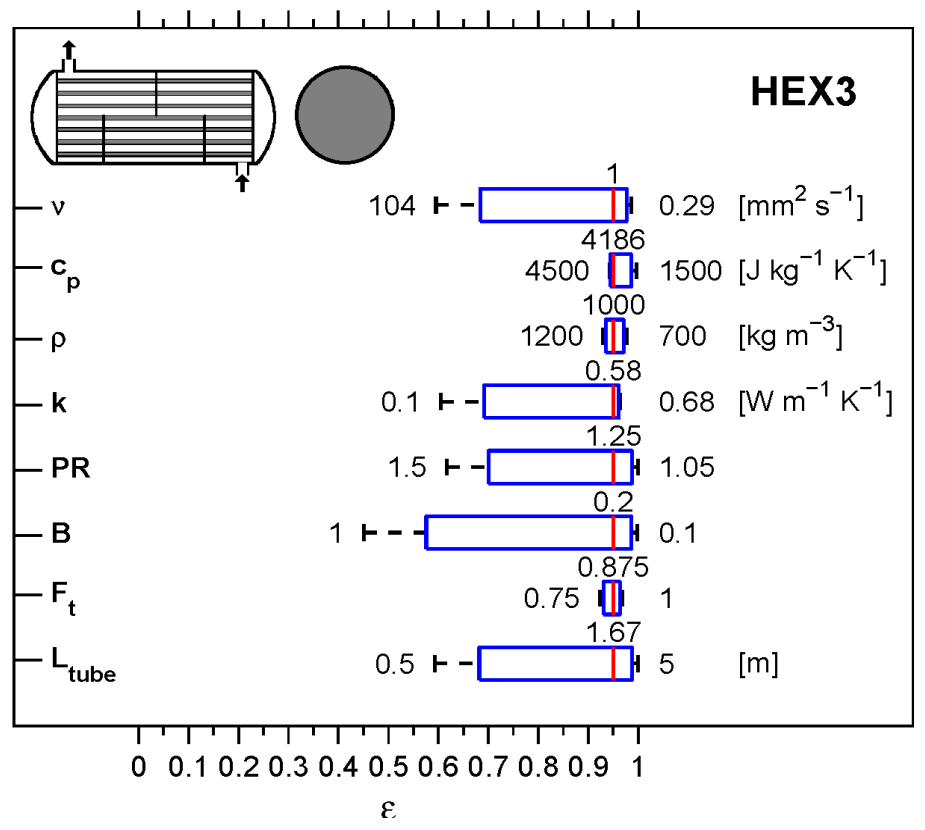

(c)

Figure 7. Sensitivity analysis for $\varepsilon$. HEX1(a); HEX2 (b); HEX3 (c).

\subsection{Heat demand analysis}

The performance study has provided a valuable indication of the effectiveness values that can be achieved for any design. However, no information on the practical regions where the systems can operate has been made available yet. The present analysis aims to identify the operational regions that correspond to practical heat exchanger designs which fulfill the hydride cooling demand and ensure a continuous exothermic reaction.

The heat generated in the solid bed is mainly due to the absorption reaction, while the compression heat of hydrogen is typically modest as it accounts for approximately $10 \%$ of the reaction heat for high pressure metal hydrides at filling pressure of 300 bar [30] and thus is neglected in this analysis, as much lower operating pressures are considered.

The time-dependent heat generated during hydrogen absorption is given as

$$
\dot{q}_{M H}=\frac{d F_{r}}{d t} w t \%_{M A X} \cdot m_{M H} \cdot \frac{\Delta H_{r}}{M W_{H 2}} \quad[\mathrm{~W}]
$$

where $F_{r}$ is the reaction progress parameter which varies between 0 at fully dehydrided conditions and 1 at fully hydride conditions. wt $\%_{M A X}$ is the weight fraction of hydrogen absorbed in the bed at saturation, $m_{M H}$ is the mass of the absorbing alloy, $\Delta H_{r}$ and $M W_{H 2}$ are the molar heat of reaction and the molecular weight of hydrogen respectively $[1,29]$. The total heat demand that must be fulfilled for the 
reaction to reach the saturation condition is the integral of Eq. (11) from $F_{r}=0$ to 1 divided by a target value for the reaction completion time. Thus, it can be written as,

$$
\dot{q}_{M H}=\frac{1}{t_{c}} \cdot w t \%_{M A X} \cdot m_{M H} \cdot \frac{\Delta H_{r}}{M W_{H 2}}[\mathrm{~W}]
$$

where $t_{r c}$ is the reaction completion time. This corresponds to the time of the heat pump cycle stage where the desired effect is generated. For a heat pump application, it is preferable to operate with a reaction time in the range of 30-60 min to avoid frequent system cycling. A relevant system needs to fulfil three main constraints: the hydride cooling must be performed to allow for a complete absorption reaction, the design must be realistically sized (including the limitations on the coolant velocity identified in Table 1) and the design must achieve appropriate reaction times.

The first constraint expresses a physical condition that must be satisfied to ensure a continuous exothermic reaction; the heat removed from the coolant must equal the heat generated in the solid bed, according to the following heat balance

$$
\dot{q}_{M H}=\dot{m}_{f, t o t} \cdot c_{p, f}\left(T_{f-m, o u t}-T_{f-m, i n}\right) \quad[\mathrm{W}]
$$

where $\dot{m}_{f, \text { tot }}$ is the total mass flow of HTF that flows through the system. The positive temperature difference between outlet and inlet describes the desired effect for the system.

The second constraint limits the results of the analysis to practical designs, as presented in Table 1. Finally, in order to calculate the reaction time in Eq. (12) we first need to assume a value for the constant hydride temperature during hydrogen absorption $\left(T_{M H}=100^{\circ} \mathrm{C}\right)$ and the $\mathrm{HTF}$ temperature at the inlet $\left(T_{f-m, \text { in }}=20^{\circ} \mathrm{C}\right)$. The outlet HTF temperature is estimated from Eq. (3) and thus the temperature difference in Eq. (13) is defined in the entire diameter-velocity space. The hydride volume hidden in the $m_{M H}$ term can be easily linked to the tube diameters for HEX2 and HEX3, while for HEX1 it is necessary to define the thickness of the solid bed placed around the tubes. This is shown in Table 3 along with the assumed reasonable values for the hydride properties.

\begin{tabular}{|c|c|c|}
\hline Parameter & Value & Unit \\
\hline wt\%MAX & $5 \%$ & $\mathrm{~kg}_{\mathrm{H} 2} \mathrm{~kg}_{\mathrm{MH}}{ }^{-1}$ \\
\hline$\Delta \mathrm{H}_{\mathrm{r}}$ & 20000 & $\mathrm{~J} \mathrm{~mol}^{-1}$ \\
\hline$\rho_{\mathrm{MH}}$ & 6000 & $\mathrm{~kg} / \mathrm{m}^{3}$ \\
\hline$\varphi$ & $50 \%$ & - \\
\hline thick.MH (HEX1 only) & 5 & $\mathrm{~mm}$ \\
\hline
\end{tabular}

Table 3. Assumed values for metal hydride properties and bed thickness.

At this point, it is possible to compute the time of reaction completion for each heat exchanger and identify the operational regions that provide practical reaction times. The results are reported in Figs. 8 
(a), (b) and (c) for HEX1, HEX2 and HEX3, respectively. The diameter range in such figures is between $0 \mathrm{~mm}$ and $40 \mathrm{~mm}$ to investigate the cooling time at relatively large tube sizes.

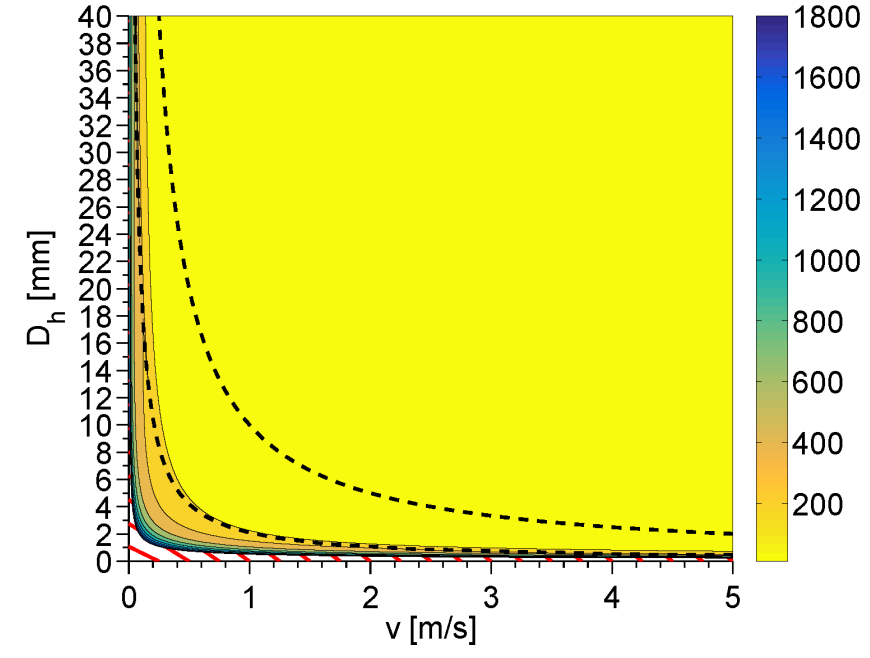

(a)

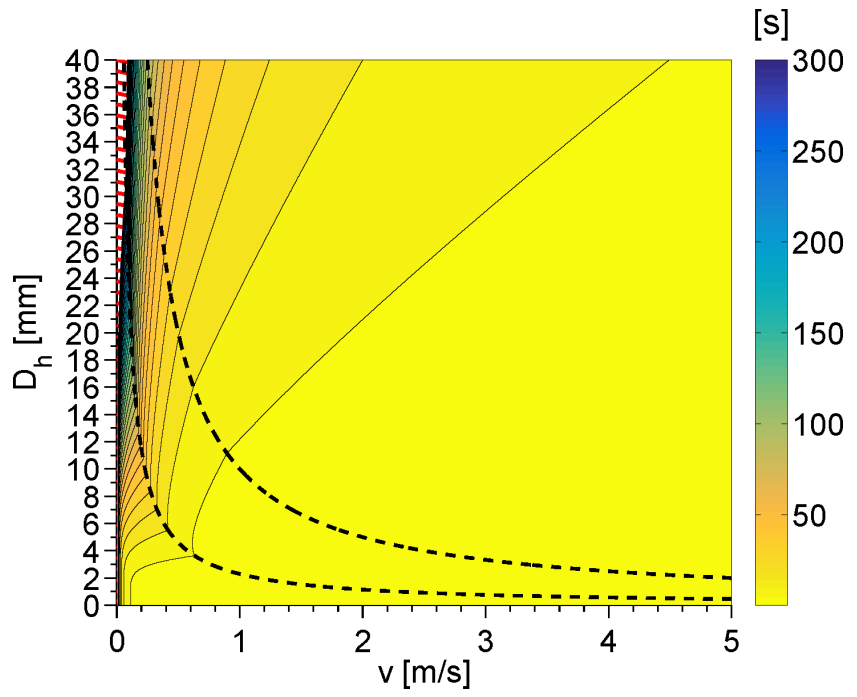

(b)

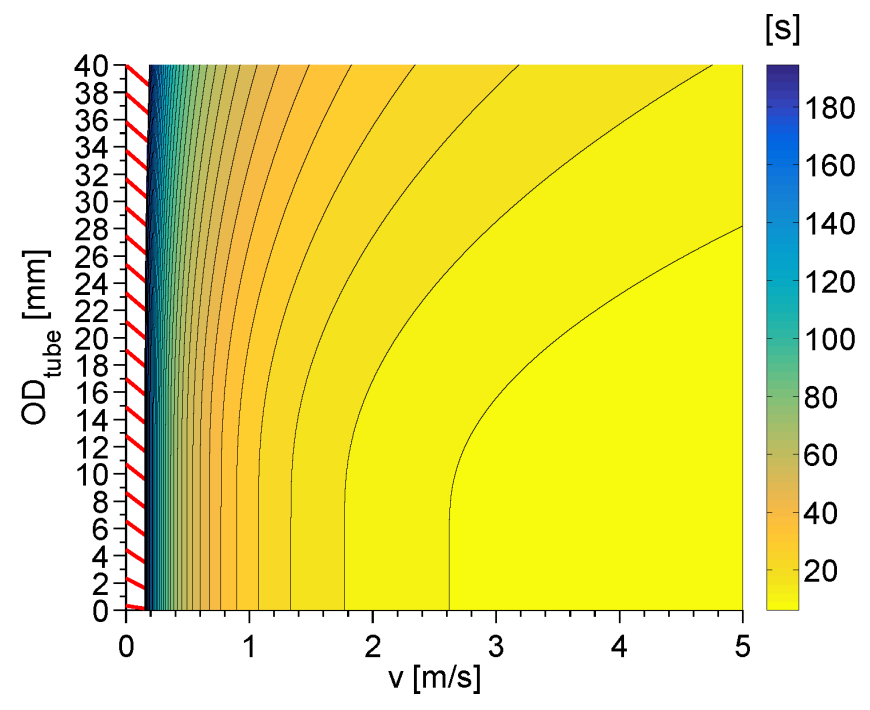

(c)

Figure 8. Time of reaction completion for HEX1 with thick. .MH $_{\text {- }} 5 \mathrm{~mm}$ (a), HEX2 with a=0.5 (b), HEX3 (c).

$$
\mathrm{L}_{\text {tube }}=1 \mathrm{~m} \text {. }
$$

The diagonal red lines represent regions where $t_{r c}$ exceeds a prescribed limit value which has been set differently for each heat exchanger in order to ease the reading of the relevant results. The limits are defined as $1800 \mathrm{~s}, 300 \mathrm{~s}$, and $200 \mathrm{~s}$ for HEX1, HEX2, and HEX3, respectively. The highest $t_{r c}$ values correspond to the region where the ratio between generated energy and transferred heat is larger. These areas refer to relatively low cooling rates and thus to small diameter and velocity values for HEX1, 
where the coolant flows inside the tubes, and to large diameters and low velocities for HEX2 and HEX3, where the $\mathrm{MH}$ is inserted in the tubes. The plots show that $t_{r c}$ assumes its maximum in the laminar regime and decreases towards the turbulent regime. As discussed in the methods section, for long-cycle MHHPs the steady state assumption better describes the portions of heat pump stage between stage cycles where the operation is actually in a quasi-steady condition. Therefore, figure 8 does not intend to be predictive on the low time-end, but rather to show what heat exchanger design space would be required for a long-operation cycle. It follows that, the results with very low reaction times are the least reliable; as it is reasonable to assume that for short reaction times (e.g. 10-20 s) the operation of the heat pump would be in transitory conditions. The results will be more accurate where the predicted reaction time is larger.

Finally, while figure 8 is meant to be more illustrative, figure 9 will present more pertinent result for selected target reaction times (i.e. 5, 30, and 60 minutes).

HEX1 presents the largest reaction times, greater by two to three orders of magnitude with respect to the other layouts. For a hydride bed thickness of $5 \mathrm{~mm}$, times greater than $300 \mathrm{~s}$ are obtained for different diameters below $2 \mathrm{~mm}$ for a wide range of velocities. Practical times of approximately $5 \mathrm{~min}$ can occur at a diameter of $2 \mathrm{~mm}$ with realistic velocities in the neighborhood of $1 \mathrm{~m} / \mathrm{s}$.

In Fig. 8 (b) the reaction time for HEX2 is presented. For a fixed aspect ratio $a$, increasing the hydraulic diameter results in relatively larger inner tube volumes, where the $\mathrm{MH}$ is located, and decreased coolant rates. However, for $a=0.5$, the HTF cross flow area is much larger than for HEX1 for the same hydraulic diameter and the ratio between generated energy and transferred heat is lower. In other words, the large cooling rates enable the transfer of all the generated heat in short times and at extremely low velocities. It can be observed that diameters of approximately $10 \mathrm{~mm}$ are needed to achieve reaction times of $1 \mathrm{~min}$. At practical sizes and fluid velocities (e.g. $D_{h}=3 \mathrm{~mm}$ and $v=0.8 \mathrm{~m} / \mathrm{s}$ ), the reaction is completed in less than $10 \mathrm{~s}$; this suggests that such a layout is not suitable for a heat pump application.

From Fig. 8 (c), showing the results for HEX3, we can draw similar conclusions as for HEX2, but with the distinction that higher reaction times occur. The coolant that flows in the shell and over the tube bank provides very large cooling rates that can transfer the heat generated inside the tubes in less than $200 \mathrm{~s}$ for a wide range of diameters and velocities. No practical reaction times are achieved for a realistically-sized design in a reasonable velocity range and the only way to extend further the reaction is to employ longer tubes. Since the hydride volume is linearly dependent upon the tube length while the coolant velocity remains constant, the reaction time increases linearly with the length. Indeed, although increasing the tube length also leads to higher heat transfer efficiencies and thus larger temperature differences in Eq. (13), their effect on the removed heat is modest at large effectiveness values and the main result consists in augmenting the hydride volume. For instance, at $20 \mathrm{~mm}$ and 1 $\mathrm{m} / \mathrm{s}$ the reaction time goes from approximately $30 \mathrm{~s}$ to $300 \mathrm{~s}$ when the tube length is increased from $1 \mathrm{~m}$ to $10 \mathrm{~m}$. It follows that the large HTF flow rates prevent the system from achieving relevant cooling times with realistically-sized tubes. These results suggest that HEX3 could be of greater interest for applications where the final goal is to dissipate the reaction heat in a short time rather than maintaining a desired temperature lift in the HTF for a long period. This is the case for storage systems in which an 
optimization analysis can be carried out to minimize the overall volume and filling time while maximizing the absorbed hydrogen mass.

In summary, we can compare the performance of the three configurations with respect to a velocity and hydride mass that is representative of a practical size and operational point. This is done in Table 4 for a hydride mass of $0.35 \mathrm{~kg}$ per tube and a velocity of $1 \mathrm{~m} / \mathrm{s}$.

Table 4. Comparison on cooling time, tube size, coolant mass flow rate and gained temperature lift between inlet and outlet for all heat exchangers for a hydride mass of $0.35 \mathrm{~kg}$ per tube and a coolant velocity of $1 \mathrm{~m} / \mathrm{s}$.

\begin{tabular}{l|ccc}
\cline { 2 - 4 } & $\begin{array}{c}\text { HEX1 } \\
\text { (thick.MH }=5 \mathrm{~mm})\end{array}$ & $\begin{array}{c}\text { HEX2 } \\
(\mathrm{a}=0.5)\end{array}$ & $\begin{array}{c}\text { HEX3 } \\
(\mathrm{Ds}=0.3 \mathrm{~m})\end{array}$ \\
\hline $\mathrm{t}_{\mathrm{rc}}[\mathrm{s}]$ & 313 & 10.9 & 21.5 \\
$\mathrm{D}_{\mathrm{h}}$ or OD $[\mathrm{mm}]$ & 2 & 15.2 & 15.2 \\
$\dot{\mathrm{m}}_{\mathrm{f}, \text { tube-or-shell }}[\mathrm{kg} / \mathrm{s}]$ & 0.0032 & 0.547 & 3.61 \\
$\left.\mathrm{~T}_{\mathrm{f}-\mathrm{m}, \text { out }}-\mathrm{T}_{\mathrm{f}-\mathrm{m}, \mathrm{in}}\right)[\mathrm{K}]$ & 43.6 & 7 & 76.9 \\
\hline
\end{tabular}

As was observed in Fig. 8, HEX2 and HEX3 provide much shorter reaction times than HEX1. This is due to their larger cooling rates; resulting in a greater ratio between removed and generated heat. For example, the mass flow rate for HEX2 is larger by two orders of magnitudes when compared to HEX1. Also, in order to contain the prescribed hydride mass, the tube size for HEX2 needs to be relatively large, moving the operational point to a region of very poor effectiveness (i.e. below 9\%) and resulting in a modest temperature increase between inlet and outlet of only $7 \mathrm{~K}$. For the HEX3, the HTF mass flow rate is larger by three orders of magnitude when compared to HEX1, making the cooling of the solid bed much more significant. However, the reaction time is greater for HEX3 than HEX2 due to the high number of hydride tubes in the shell (i.e. 208 tubes). Once again the significant temperature increase provided by HEX3 suggests that such a configuration is more suitable to effectively and rapidly transfer the heat to the HTF rather than sustain the cooling performance for the duration required for a MHHP application. By considering both the HTF's temperature increase, an indicator of the desired effect of the heat pump, and the cooling times, it can be concluded that HEX1 is the most promising design. For this reason, it should be further investigated with respect to some target reaction times and using the hydride bed thickness as the free variable. 


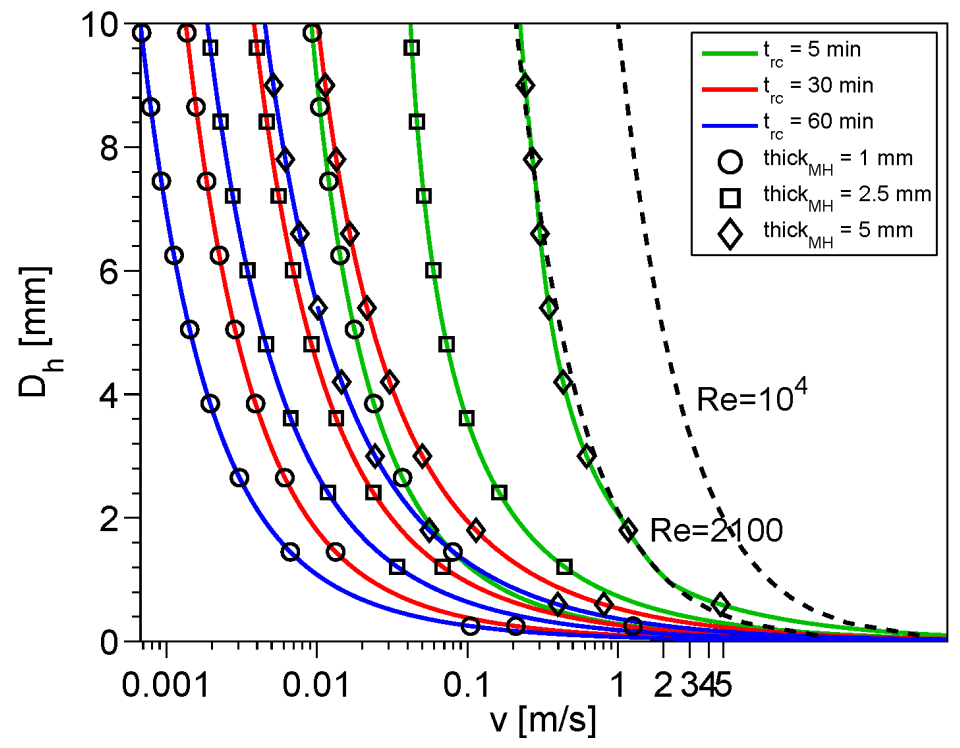

Figure 9. Time of reaction completion for some target values and representative solid bed thicknesses for HEX1.

This investigation is shown in Fig. 9, where three $t_{r c}$ target values (i.e. 5, 30, 60 min) are plotted for three representative values of the hydride bed thickness, $1 \mathrm{~mm}, 2.5 \mathrm{~mm}$, and $5 \mathrm{~mm}$. A semi-logarithmic plot is used to better appreciate the points that lie on the operational curves at velocities below $1 \mathrm{~m} / \mathrm{s}$. The black dashed lines correspond to the flow regime transitions and are plotted for consistency with the previous plots and to provide additional relevant information. It should be noted that all the curves essentially lie in the laminar regime.

For a given thickness, the lines that refer to greater times are closer to the $y$-axis, which is representative of the limit condition of null mass flow rates and thus of non-practical designs. Similarly, when we compare the lines that correspond to a certain reaction time (i.e. the same color), lower values of velocity belong to smaller thickness values.

Reaction times of 5 min can be obtained for realistically-sized designs starting from $5 \mathrm{~mm}$ of bed thickness and velocity values around $1 \mathrm{~m} / \mathrm{s}$.

However, as it is preferable to operate at relatively high $t_{r c}$, it is more relevant to focus on the lines that refer to target reaction times of 30 and 60 min. As shown in Fig. 9, such lines correspond to designs characterized by unrealistic diameters and/or velocities. For example, for a $5 \mathrm{~mm}$ thickness and a $2 \mathrm{~mm}$ diameter, extremely low velocities are needed to provide reaction times of 30 and $60 \mathrm{~min}: 0.1 \mathrm{~m} / \mathrm{s}$ and $0.05 \mathrm{~m} / \mathrm{s}$, respectively. Such velocity values are too small to avoid the risk of debris formation and ensure a continuous operation in absence of constant monitoring and periodical cleaning. In practice, for relevant tube sizes and fluid velocities, simulations have shown that for HEX1 is possible to achieve a reaction time of 30 min by either enlarging the metal hydride bed around the tubes or recirculating the HTF in a multi-pass configuration. If we consider cooling tubes of $2 \mathrm{~mm}$ and velocities of $0.8 \mathrm{~m} / \mathrm{s}$, a reaction time of $30 \mathrm{~min}$ can be achieved, for instance, by designing an annular bed thickness of $10 \mathrm{~mm}$ with a length of $2 \mathrm{~m}$ or by recirculating the heat transfer fluid eight times through a $5 \mathrm{~mm}$ bed. The former option provides a larger system, whereas the latter solution is more 
compact but at the expenses of a smaller total amount of heated HTF and larger pressure drops. Therefore, depending on which requirement is the most stringent (i.e. volume, pressure drops) the design can be adapted to fulfill the operating requirements listed in table 1.

The final selection of the design should also account for the performance values and thus the actual temperature increase than can be achieved for a target time. It must be noted that for HEX1, an increase in the tube length has a positive effect on both the effectiveness and the reaction time; the larger amount of heat is accounted for by an increase in the hydride mass. It is also possible to further increase the reaction time by employing thicker solid beds around the cooling tubes. Both options provide increased performance and reaction time and reduced the overall system volume, which can be the most stringent constraint in some applications.

\section{Conclusions}

This work presents a design procedure to select effective heat exchanger designs that can be used in stationary MHHP applications. A thermal model, designed to be independent of the properties of the specific absorbing alloy, along with mechanical and operational constraints, guides the analysis of three configurations of shell-and-tube heat exchangers. With the first configuration, HEX1, the coolant flows inside tubes surrounded by metal hydrides. In HEX2, the metal hydride is packed in the tubes and the coolant flows parallel to the tube. In HEX3, the metal hydride is also packed in the tube, but the coolant circulates in combined cross-parallel flow over the tube bank. The main outcomes and conclusions derived from the modeling results are:

- Performance and pressure drop maps for reasonable tube sizes and a wide velocity range are obtained for each heat exchanger candidate; giving the reader all the information needed to select a suitable solution in a pre-design stage.

- The effectiveness values seem to be modestly influenced by the particular correlation used to compute the HTF convection coefficient. It follows that any trustable Nusselt number correlations investigated in this study provide a sufficiently correct estimation of the performance, with a maximum relative difference of $13 \%$ for HEX1 in the turbulent regime.

- The tube length is the design parameter that affects HEX1 performance the most due to its linear effect on the heat transfer area which influences the exponent in the index of performance formulation. It also has a significant effect on the heat transfer effectiveness values for HEX3, although the baffle space is found to be the most sensitive parameter for such a configuration. Another parameter that can be adjusted towards higher efficiencies is the aspect ratio $a$ for the tubein-tube configuration of HEX2. However, the sensitivity analysis shows that a positive effect is obtained when its value tends to unity, and thus to a condition where the cross flow area and the mass flow are nearly zero, resulting in a negligible heat transfer rate.

- HEX3 is the solution that provides the greatest performance per unit of active tube length; modestly distributed pressure drops can be achieved for a tube diameter around $20 \mathrm{~mm}$ in the optimum velocity range. 
- The combination of the performance and heat demand analyses provides a valuable tool to decide whether a certain heat exchanger layout is suitable for a MHHP application and aid in the selection of practical designs. Both HEX2 and HEX3 configurations lead to non-practical designs when relevant reaction times are targeted. HEX1 is found to be the only layout that can provide realistically-sized designs that fulfill the requirements and respect the constraints defined in this study. Longer tubes positively affect both the temperature increase of the coolant and the reaction times. Also, the possibility of augmenting the reaction times by enlarging the bed thickness around the cooling tubes is an interesting feature of this layout for a heat pump application.

- The design that can satisfy the performance requirements with respect of all the design criteria was found to be HEX1 with the following parameters: $2 \mathrm{~mm}$ diameter tubes surrounded by a $10 \mathrm{~mm}$ bed thickness with a total active length of $3 \mathrm{~m}$, operating at a HTF velocity of $0.8 \mathrm{~m} / \mathrm{s}$. Such a system provides an efficiency of $85 \%$ (i.e. $T_{f-m, \text { out }}=88^{\circ} \mathrm{C}$ for $T_{M H}=100^{\circ} \mathrm{C}$ and $T_{f-m, \text { in }}=20^{\circ} \mathrm{C}$ ), an overall pressure loss of $0.2 \mathrm{bar}$, and achieves a reaction time of $40 \mathrm{~min}$.

- The thermal model can easily be tailored to include information on the hydride thermal properties, providing a more specific design for any application.

\section{Acknowledgements}

The Danish Research Council through the Hyfill-Fast International Research Project is acknowledged for collaboration support. The authors would also like to thank the Industrial Technology Research Institute of Taiwan for their support on the project.

Sandia National Laboratories is a multi-program laboratory managed and operated by Sandia Corporation, a wholly owned subsidiary of Lockheed Martin Corporation, for the U.S. Department of Energy's National Nuclear Security Administration under contract DE-AC04-94AL85000.

\section{Appendix. Nu Correlations}

This appendix defines the nominal and alternative $\mathrm{Nu}$ correlations discussed in the results section of this work.

The alternative Nu correlations are given for each heat exchanger in Table 5 with respect to their name, Re interval, and flow regime of validity. For additional information, the reader is referred to the listed references, as a detailed description of such correlations falls outside the objective of the present study. 
Table 5. List of the nominal equations considered in the Nu correlation analysis.

\begin{tabular}{|c|c|c|c|}
\hline Flow regime & HEX1 & HEX2 & HEX3 \\
\hline Laminar & $\begin{array}{c}\text { Sieder-Tate, } \\
\text { pp. 5-15 [36] } \\
(\operatorname{Re}<2100)\end{array}$ & $\begin{array}{c}\text { Martin, } \\
\text { pp.702-703 } \\
{[38]} \\
(\operatorname{Re}<2300)\end{array}$ & \multirow{3}{*}{$\begin{array}{l}\text { Bell-Delaware, } \\
\text { method, pp. } \\
\text { 317-320 [35] } \\
\text { (any Re) }\end{array}$} \\
\hline Transition & $\begin{array}{c}\text { Hausen, } \\
\text { pp. } 5-16 \\
{[36]\left(2100 \leq \mathrm{Re}<10^{4}\right)}\end{array}$ & $\begin{array}{c}\text { See p.703 Ref. } \\
{[38]} \\
\left(2300<\operatorname{Re}<10^{4}\right)\end{array}$ & \\
\hline Turbulent & $\begin{array}{l}\text { Dittus-Boelter-- } \\
\text { Colburn*, } \\
\text { pp. 5-16 [33] } \\
\left(\operatorname{Re} \geq 10^{4}\right)\end{array}$ & $\begin{array}{c}\text { Gnielinski, } \\
\text { p.703 [38] } \\
\left(\operatorname{Re} \geq 10^{4}\right)\end{array}$ & \\
\hline
\end{tabular}

*modified Dittus-Boelter with Colburn analogy.

The alternative correlations are reported in Table 6.

Table 6. List of the alternative equations considered in the $\mathrm{Nu}$ correlation analysis.

\begin{tabular}{|c|c|c|c|c|}
\hline Flow regime & \multicolumn{2}{|c|}{ HEX1 } & HEX2 & HEX3 \\
\hline Laminar & $\begin{array}{l}\text { Mills, [43] } \\
(\operatorname{Re}<2100)\end{array}$ & NA & NA & Kern method*, \\
\hline Transition & NA & & NA & pp. 307-309 \\
\hline Turbulent & $\begin{array}{c}\text { Dittus-Boelter, } \\
\text { pp. } 516-517 \\
{[33]\left(\mathrm{Re} \geq 10^{4}\right)}\end{array}$ & $\begin{array}{c}{[33]} \\
\left(3000 \leq \operatorname{Re}<5 \times 10^{6}\right)\end{array}$ & $\begin{array}{l}\text { Dirker-Meyer, } \\
{[44]\left(\operatorname{Re} \geq 10^{4}\right)}\end{array}$ & $\begin{array}{c}{[35]} \\
\left(2000 \leq \operatorname{Re} \leq 10^{6}\right)\end{array}$ \\
\hline
\end{tabular}

*The Kern method actually refers to a correlation found by McAdams.

\section{Nomenclature}

$A_{\text {cross }} \quad$ cross flow area, $\mathrm{m}^{2}$

$A_{\text {hex }} \quad$ heat transfer area, $\mathrm{m}^{2}$

a aspect ratio

$B$ relative baffle spacing, \% or absolute value

$C_{1} \quad$ geometric constant defined in Eq. (A.7)

$C_{l} \quad$ tube clearance, $\mathrm{m}$

$C_{t} \quad$ tube layout constant

CTP tube count constant for one tube pass

$c_{p} \quad$ heat capacity, $\mathrm{J} \mathrm{mol}^{-1} \mathrm{~K}^{-1}$ or $\mathrm{J} \mathrm{kg}^{-1} \mathrm{~K}^{-1}$

D diameter of a tube, $\mathrm{m}$ or $\mathrm{mm}$

$D_{s} \quad$ inner diameter of the shell for HEX3, m or mm 


\begin{tabular}{|c|c|}
\hline$\Delta H_{r}$ & enthalpy of reaction, $\mathrm{J} \mathrm{mol}^{-1}$ \\
\hline$\Delta p$ & distribute pressure losses, $\mathrm{Pa}$ \\
\hline$F$ & index of performance \\
\hline$F_{r}$ & reaction progress \\
\hline$F_{t}$ & temperature factor \\
\hline$f_{r}$ & fraction of maximum heat of absorption reaction \\
\hline$G$ & geometrical exponential term, $\mathrm{m}^{2}$ or - \\
\hline$k$ & thermal conductivity, $\mathrm{W} \mathrm{m}{ }^{-1} \mathrm{~K}^{-1}$ \\
\hline$L$ & length, m \\
\hline$m$ & mass, kg, \\
\hline$\dot{m}$ & mass flow rate, $\mathrm{kg} \mathrm{s}^{-1}$ \\
\hline$M W$ & molecular weight, $\mathrm{kg} \mathrm{mol}^{-1}$ \\
\hline$N_{p}$ & number of tube passes \\
\hline $\mathrm{Nu}$ & Nusselt number \\
\hline$O D$ & tube outer diameter, $\mathrm{m}$ or $\mathrm{mm}$ \\
\hline$P$ & thermo-physical parameters term, $\mathrm{m}^{3} \mathrm{~K} \mathrm{~J}^{-1}$ \\
\hline$P R$ & outer tube to pitch ratio for HEX3 \\
\hline$P_{t}$ & tube pitch, m \\
\hline$P_{\text {tube }}$ & perimeter of tube, $\mathrm{m}$ \\
\hline$\dot{q}$ & heat flow rate, $\mathrm{W}$ \\
\hline$q^{\prime \prime}$ & heat flux, $\mathrm{W} \mathrm{m}^{-2}$ \\
\hline$R e$ & Reynolds number \\
\hline$T$ & temperature, $\mathrm{K}$ or ${ }^{\circ} \mathrm{C}$ \\
\hline$t$ & time, s \\
\hline$t_{r c}$ & time of reaction completion, $\mathrm{s}$ \\
\hline $\bar{U}$ & mean overall heat transfer coefficient, $\mathrm{W} \mathrm{m}^{-2} \mathrm{~K}^{-1}$ \\
\hline$V$ & 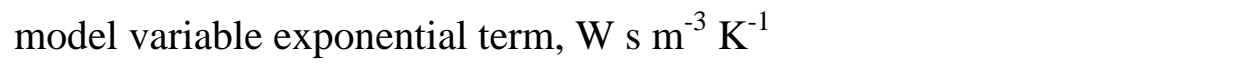 \\
\hline$v$ & velocity of the heat transfer fluid, $\mathrm{m} \mathrm{s}^{-1}$ \\
\hline$v_{o, m}$ & mean value of the optimum velocity range, $\mathrm{m} \mathrm{s}^{-1}$ \\
\hline$w t \%_{M A X}$ & weight fraction of hydrogen absorbed in the bed at saturation, $\mathrm{kg}_{\mathrm{H} 2} \mathrm{~kg}_{\mathrm{MH}}{ }^{-1}$ \\
\hline$x$ & spatial coordinate along the tube length, $\mathrm{m}$ \\
\hline
\end{tabular}

\section{Greek symbols}

$\begin{array}{ll}\alpha & \text { permeability of the metal hydride, } \mathrm{m}^{2} \\ \varepsilon & \text { effectiveness, \% or absolute value } \\ \rho & \text { density, } \mathrm{kg} \mathrm{m}^{-3} \\ \varphi & \text { porosity }\end{array}$




$\begin{array}{ll}\text { Subscripts } & \\ D & \text { demand } \\ f & \text { fluid } \\ H_{2} & \text { hydrogen } \\ h & \text { hydraulic } \\ i & \text { inner } \\ \text { in } & \text { inlet } \\ m & \text { mean } \\ \text { max } & \text { maximum, referred to saturation value } \\ o & \text { outer } \\ \text { out } & \text { outlet } \\ r & \text { reaction } \\ t & \text { tube } \\ \text { tot } & \text { total }\end{array}$

$\begin{array}{ll}\text { Abbreviations } \\ \text { COP } & \text { Coefficient Of Performance } \\ \text { HSL } & \text { Hydrogen System Laboratory, at Purdue University } \\ \text { HTF } & \text { Heat Transfer Fluid } \\ \text { Lam. } & \text { Laminar flow regime } \\ \text { LHS } & \text { Left Hand Side } \\ \text { MH } & \text { Metal Hydride } \\ \text { MHHP } & \text { Metal Hydride Heat Pump } \\ \text { RHS } & \text { Right Hand Side } \\ \text { Turb. } & \text { Turbulent flow regime } \\ \text { thick. } & \text { thickness }\end{array}$

\section{References}

[1] A. Mazzucco, M. Dornheim, M. Sloth, T. R. Jensen, J. O. Jensen, and M. Rokni, "Bed geometries, fueling strategies and optimization of heat exchanger designs in metal hydride storage systems for automotive applications: A review,” Int. J. Hydrogen Energy, vol. 39, no. 30, pp. 17054-17074, Oct. 2014.

[2] L. E. Klebanoff and J. O. Keller, "5 Years of hydrogen storage research in the U.S. DOE Metal Hydride Center of Excellence (MHCoE),” Int. J. Hydrogen Energy, vol. 38, no. 11, pp. 4533-4576, Apr. 2013. 
[3] B. Sakintuna, F. Lamaridarkrim, and M. Hirscher, "Metal hydride materials for solid hydrogen storage: A review玄,” Int. J. Hydrogen Energy, vol. 32, no. 9, pp. 1121-1140, Jun. 2007.

[4] A. I. Solovey and V. P. Frolov, "Metal hydride heat pump for watering systems," J. Hydrogen Energy, vol. 26, pp. 707-709, 2001.

[5] M. V. Lototskyy, V. a. Yartys, B. G. Pollet, and R. C. Bowman, "Metal hydride hydrogen compressors: A review,” Int. J. Hydrogen Energy, vol. 39, no. 11, pp. 5818-5851, Apr. 2014.

[6] P. Muthukumar and M. Groll, "Metal hydride based heating and cooling systems: A review," Int. J. Hydrogen Energy, vol. 35, no. 8, pp. 3817-3831, Apr. 2010.

[7] M. H. Bhuiya, A. Kumar, and K. J. Kim, "Metal hydrides in engineering systems , processes , and devices : A review of non-storage applications,” Int. J. Hydrogen Energy, vol. 40, no. 5, pp. 2231-2247, 2015.

[8] M. Raju and S. Kumar, "Optimization of heat exchanger designs in metal hydride based hydrogen storage systems,” Int. J. Hydrogen Energy, vol. 37, no. 3, pp. 2767-2778, Feb. 2012.

[9] H. Dhaou, N. Ben Khedher, S. Mellouli, A. Souahlia, F. Askri, A. Jemni, and S. B. Nasrallah, "Improvement of thermal performance of spiral heat exchanger on hydrogen storage by adding copper fins,” Int. J. Therm. Sci., vol. 50, no. 12, pp. 2536-2542, Dec. 2011.

[10] S. N. Nyamsi, F. Yang, and Z. Zhang, “An optimization study on the finned tube heat exchanger used in hydride hydrogen storage system - analytical method and numerical simulation,” Int. J. Hydrogen Energy, vol. 37, no. 21, pp. 16078-16092, Nov. 2012.

[11] M. Visaria, I. Mudawar, and T. Pourpoint, "Enhanced heat exchanger design for hydrogen storage using high-pressure metal hydride - Part 2. Experimental results,” Int. J. Heat Mass Transf., vol. 54, no. 1-3, pp. 424-432, Jan. 2011.

[12] M. Visaria and I. Mudawar, "Coiled-tube heat exchanger for High-Pressure Metal Hydride hydrogen storage systems - Part 1. Experimental study,” Int. J. Heat Mass Transf., vol. 55, no. 5-6, pp. 1782-1795, Feb. 2012.

[13] J. Payá, M. Linder, R. Mertz, and J. M. Corberán, “Analysis and optimization of a metal hydride cooling system,” Int. J. Hydrogen Energy, vol. 36, no. 1, pp. 920-930, Jan. 2011.

[14] A. Satheesh and P. Muthukumar, "Performance investigations of a single-stage metal hydride heat pump,” Int. J. Hydrogen Energy, vol. 35, no. 13, pp. 6950-6958, Jul. 2010. 
[15] B. Satya Sekhar and P. Muthukumar, "Performance tests on a double-stage metal hydride based heat transformer,” Int. J. Hydrogen Energy, vol. 38, no. 35, pp. 15428-15437, Nov. 2013.

[16] S. Anbarasu, P. Muthukumar, and S. C. Mishra, "Tests on LmNi4.91Sn0.15 based Solid State Hydrogen storage device with embedded cooling tubes - Part A : Absorption process,” Int. J. Hydrogen Energy, vol. 39, no. 7, pp. 3342-3351, 2014.

[17] H. Choi and A. F. Mills, "Heat and mass transfer in metal hydride beds for heat pump applications," Int. J. Heat Mass Transf., vol. 33, no. 6, pp. 1281-1288, Jun. 1990.

[18] H. Bjurstrom, Y. Komazaki, and S. Suda, "The dynamics of hydrogen transfer in a metal hydride heat pump,” J. Less Common Met., vol. 131, pp. 225-234, 1987.

[19] J. Payá, M. Linder, E. Laurien, and J. M. Corberán, "Dynamic model and experimental results of a thermally driven metal hydride cooling system,” Int. J. Hydrogen Energy, vol. 34, no. 7, pp. 3173-3184, Apr. 2009.

[20] A. Satheesh, P. Muthukumar, and A. Dewan, "Computational study of metal hydride cooling system," Int. J. Hydrogen Energy, vol. 34, no. 7, pp. 3164-3172, Apr. 2009.

[21] H. P. Klein and M. Groll, "Development of a two-stage metal hydride system as topping cycle in cascading sorption systems for cold generation,” Appl. Therm. Eng., vol. 22, no. 6, pp. 631-639, Apr. 2002.

[22] A. S. Chernikov, L. A. Izhvanov, A. I. Solovey, V. P. Frolov, and Y. I. Shanin, “An installation for water cooling based on a metal hydride heat pump,” J. Alloys Compd., vol. 330-332, pp. 907-910, Jan. 2002.

[23] B. Satya Sekhar, S. P. Pailwan, and P. Muthukumar, "Studies on metal hydride based single-stage heat transformer,” Int. J. Hydrogen Energy, vol. 38, no. 17, pp. 7178-7187, Jun. 2013.

[24] H. I. Abelson and J. S. Horowitz, “Thermodynamic analysis of a MH heat pump,” Energy, vol. 5, no. 4, pp. 237-43, 1981.

[25] F. S. Yang, Z. X. Zhang, G. X. Wang, Z. W. Bao, J. C. Diniz da Costa, and V. Rudolph, "Numerical study of a metal hydride heat transformer for low-grade heat recovery," Appl. Therm. Eng., vol. 31, no. 14-15, pp. 2749-2756, Oct. 2011.

[26] T. G. Voskuilen and T. L. Pourpoint, "Methods for quantifying the influences of pressure and temperature variation on metal hydride reaction rates measured under isochoric conditions.," Rev. Sci. 
Instrum., vol. 84, no. 11, p. 115102, Nov. 2013.

[27] T. Voskuilen, Y. Zheng, and T. Pourpoint, "Development of a Sievert apparatus for characterization of high pressure hydrogen sorption materials,” Int. J. Hydrogen Energy, vol. 35, no. 19, pp. 1038710395, Oct. 2010.

[28] S. Flueckiger, T. Voskuilen, T. Pourpoint, T. S. Fisher, and Y. Zheng, "In situ characterization of metal hydride thermal transport properties,” Int. J. Hydrogen Energy, vol. 35, no. 2, pp. 614-621, Jan. 2010.

[29] T. L. Pourpoint, V. Velagapudi, I. Mudawar, Y. Zheng, and T. S. Fisher, “Active cooling of a metal hydride system for hydrogen storage,” Int. J. Heat Mass Transf., vol. 53, no. 7-8, pp. 1326-1332, Mar. 2010 .

[30] M. Visaria, I. Mudawar, T. Pourpoint, and S. Kumar, "Study of heat transfer and kinetics parameters influencing the design of heat exchangers for hydrogen storage in high-pressure metal hydrides," Int. $J$. Heat Mass Transf., vol. 53, no. 9-10, pp. 2229-2239, Apr. 2010.

[31] M. Visaria and I. Mudawar, "Experimental investigation and theoretical modeling of dehydriding process in high-pressure metal hydride hydrogen storage systems," Int. J. Hydrogen Energy, vol. 37, no. 7, pp. 5735-5749, Apr. 2012.

[32] T. G. Voskuilen, E. L. Waters, and T. L. Pourpoint, "A comprehensive approach for alloy selection in metal hydride thermal systems,” Int. J. Hydrogen Energy, vol. 39, no. 25, pp. 13240-13254, Aug. 2014.

[33] F. P. Incropera, D. P. DeWitt, T. L. Bergman, and A. S. Lavine, Fundamentals of Heat and Mass Transfer, vol. 6th. John Wiley \& Sons, 2007.

[34] "Standards of the Tubular Exchanger Manufacturers Association,” 8th Edition. Tarrytown, New York, 1999.

[35] S. Kakaç and H. Liu, Heat exchangers: selection, rating, and thermal design, 2nd ed. CRC Press, 2002.

[36] R. Perry, D. Green, and J. Maloney, Perry’s chemical engineer's handbook, 6th ed. McGraw Hill Publishers, 1984.

[37] V. Gnielinski, "Berechnung des Druckverlustes in glatten konzentrischen Ringspalten bei ausgebildeter laminarer und turbulenter isothermer Strömung,” Chemie Ing. Tech., vol. 79, no. 1-2, pp. 91-95, Feb. 2007.

[38] VDI, Ed., VDI-Gesellschaft Verfahrenstechnik und Chemieingenieurwesen, 2nd ed. Dusseldorf (DE): 
Springer, 2010.

[39] S. W. Churchill, "Friction-factor equation spans all fluid-flow regimes,” Chem. Eng., vol. 84, no. 24, p. 1977, 1977.

[40] P. L. Young, T. P. Brackbill, and S. G. Kandlikar, "Estimating Roughness Parameters Resulting From Various Machining Techniques for Fluid Flow Applications,” ASME 5th Int. Conf. Nanochannels, Microchannels, Minichannels, pp. 827-836, 2007.

[41] M. Raju, J. P. Ortmann, and S. Kumar, "System simulation model for high-pressure metal hydride hydrogen storage systems,” Int. J. Hydrogen Energy, vol. 35, no. 16, pp. 8742-8754, Aug. 2010.

[42] S. Anbarasu, P. Muthukumar, and S. C. Mishra, "Tests on LmNi4.91Sn0.15 based solid state hydrogen storage device with embedded cooling tubes - Part B : Desorption process,” Int. J. Hydrogen Energy, vol. 39, no. 10, pp. 4966-4972, 2014.

[43] A. F. Mills, Heat Transfer, 2nd ed. New Jersey: Prentice Hall, 1999.

[44] J. Dirker and J. P. Meyer, “Convective Heat Transfer Coefficients in Concentric Annuli," Heat Transf. Eng., vol. 26, no. 2, pp. 38-44, Mar. 2005.

[45] V. Gnielinski, "Heat Transfer Coefficients for Turbulent Flow in Concentric Annular Ducts," Heat Transf. Eng., vol. 30, no. 6, pp. 431-436, May 2009.

[46] J. W. Palen, Ed., Heat Exchanger Sourcebook. Alhambra, CA: Hemisphere Publishing Corp., 1986.

[47] “Technical Data Sheet.” Dow Chemical Company, 1997.

[48] “Thermal Properties Calculator v6.4. Paratherm Ltd.” 2013. [Online]. Available: http://paracalc.paratherm.com. 